\title{
Review \\ Cyclodextrins: Structural, Chemical, and Physical Properties, and Applications
}

\author{
Benjamin Gabriel Poulson ${ }^{1}{ }^{(}$, , Qana A. Alsulami ${ }^{2}{ }^{\circledR}$, Abeer Sharfalddin ${ }^{2}{ }^{\circledR}$, Emam. F. El Agammy ${ }^{3}$, \\ Fouzi Mouffouk ${ }^{4}{ }^{\circ}$, Abdul-Hamid Emwas ${ }^{5}{ }^{\oplus}$, Lukasz Jaremko ${ }^{6}\left(\mathbb{D}\right.$ and Mariusz Jaremko ${ }^{6, *}$
}

1 Division of Biological and Environmental Sciences and Engineering (BESE), King Abdullah University of Science and Technology (KAUST), Thuwal 23955-6900, Saudi Arabia; benjamingabriel.poulson@kaust.edu.sa

2 Department of Chemistry, Faculty of Science, King Abdulaziz University, P.O. Box 80203, Jeddah 21589, Saudi Arabia; qalselami@kau.edu.sa (Q.A.A.); sharfalddin.aa@hotmail.com (A.S.)

3 Physics Department, College of Science, Jouf University, P.O. Box 2014, Sakaka 72345, Saudi Arabia; efelagamy@ju.edu.sa

4 Department of Chemistry, Kuwait University, P.O. Box 5969, Safat 13060, Kuwait; fmouffouk@ku.edu.kw

5 Core Labs, King Abdullah University of Science and Technology (KAUST), Thuwal 23955-6900, Saudi Arabia; abdelhamid.emwas@kaust.edu.sa

6 Smart-Health Initiative (SHI) and Red Sea Research Center (RSRC), Division of Biological and Environmental Sciences and Engineering (BESE), King Abdullah University of Science and Technology (KAUST), Thuwal 23955-6900, Saudi Arabia; lukasz.jaremko@kaust.edu.sa

* Correspondence: mariusz.jaremko@kaust.edu.sa

\section{check for}

updates

Citation: Poulson, B.G.; Alsulami, Q.A.; Sharfalddin, A.; El Agammy, E.F.; Mouffouk, F.; Emwas, A.-H.; Jaremko, L.; Jaremko, M. Cyclodextrins: Structural, Chemical, and Physical Properties, and Applications. Polysaccharides 2022, 3, 1-31. https://doi.org/10.3390/ polysaccharides 3010001

Academic Editors: Cédric Delattre, Paolina Lukova and Guillaume Pierre

\section{Received: 15 October 2021}

Accepted: 21 December 2021

Published: 28 December 2021

Publisher's Note: MDPI stays neutral with regard to jurisdictional claims in published maps and institutional affiliations.

Copyright: (C) 2021 by the authors. Licensee MDPI, Basel, Switzerland. This article is an open access article distributed under the terms and conditions of the Creative Commons Attribution (CC BY) license (https:// creativecommons.org/licenses/by/ $4.0 /)$.

\begin{abstract}
Due to their unique structural, physical and chemical properties, cyclodextrins and their derivatives have been of great interest to scientists and researchers in both academia and industry for over a century. Many of the industrial applications of cyclodextrins have arisen from their ability to encapsulate, either partially or fully, other molecules, especially organic compounds. Cyclodextrins are non-toxic oligopolymers of glucose that help to increase the solubility of organic compounds with poor aqueous solubility, can mask odors from foul-smelling compounds, and have been widely studied in the area of drug delivery. In this review, we explore the structural and chemical properties of cyclodextrins that give rise to this encapsulation (i.e., the formation of inclusion complexes) ability. This review is unique from others written on this subject because it provides powerful insights into factors that affect cyclodextrin encapsulation. It also examines these insights in great detail. Later, we provide an overview of some industrial applications of cyclodextrins, while emphasizing the role of encapsulation in these applications. We strongly believe that cyclodextrins will continue to garner interest from scientists for many years to come, and that novel applications of cyclodextrins have yet to be discovered.
\end{abstract}

Keywords: cyclodextrins; host-guest chemistry; supramolecular chemistry; drug delivery research

\section{Introduction-Brief History of Cyclodextrins \& Their Applications}

Cyclodextrins (CDs) were formally discovered in 1891 [1] as Antoine Villers studied enzymatic degradation of potato starch in bacteria [2,3]. Villers isolated two compounds (most likely $\alpha-C D$ and $\beta-C D[4]$ ) with properties similar to those of cellulose (i.e., resistance to acid hydrolysis, and non-reducing properties) [4,5]. He consequently named them "cellulosines" [6]. Franz Schardinger, the so-called "Founding Father" of cyclodextrin chemistry, renamed these two compounds dextrins [5,6], from which the modern name of "cyclodextrins" originates. In 1939, Karl Freudenberg and his co-workers published a full description of the two separated compounds [7]. In 1954, Friedrich Cramer focused on separating and purifying CDs naturally, and studied CD-guest inclusion complexes in different states [8].

Even though CDs were discovered well over a century ago, the number of papers about cyclodextrins from 1955 to 1975 was minimal (See Figure 1) [2,9-11]. This low 
number partially due to the (erroneous) statement that CDs were toxic. Dexter French reported this in a criticical review of CDs in 1957 [5]. He and B. H. Thomas fed rats fed small quantities of highly purified $\beta-C D$, and oddly enough, all subsequently died. These results, however, were unpublished, and the authors did not explain the cause of death [5]. The methods French and Thomas used are questionable [4], and have since been proven incorrect [4]; other factors such as solubility [12-14], chemical modification [15-18], route of administration (oral, intravenous, topical, etc.) [19-21] must be taken into account when considering CDs' toxicity, which varies even among the native CDs.

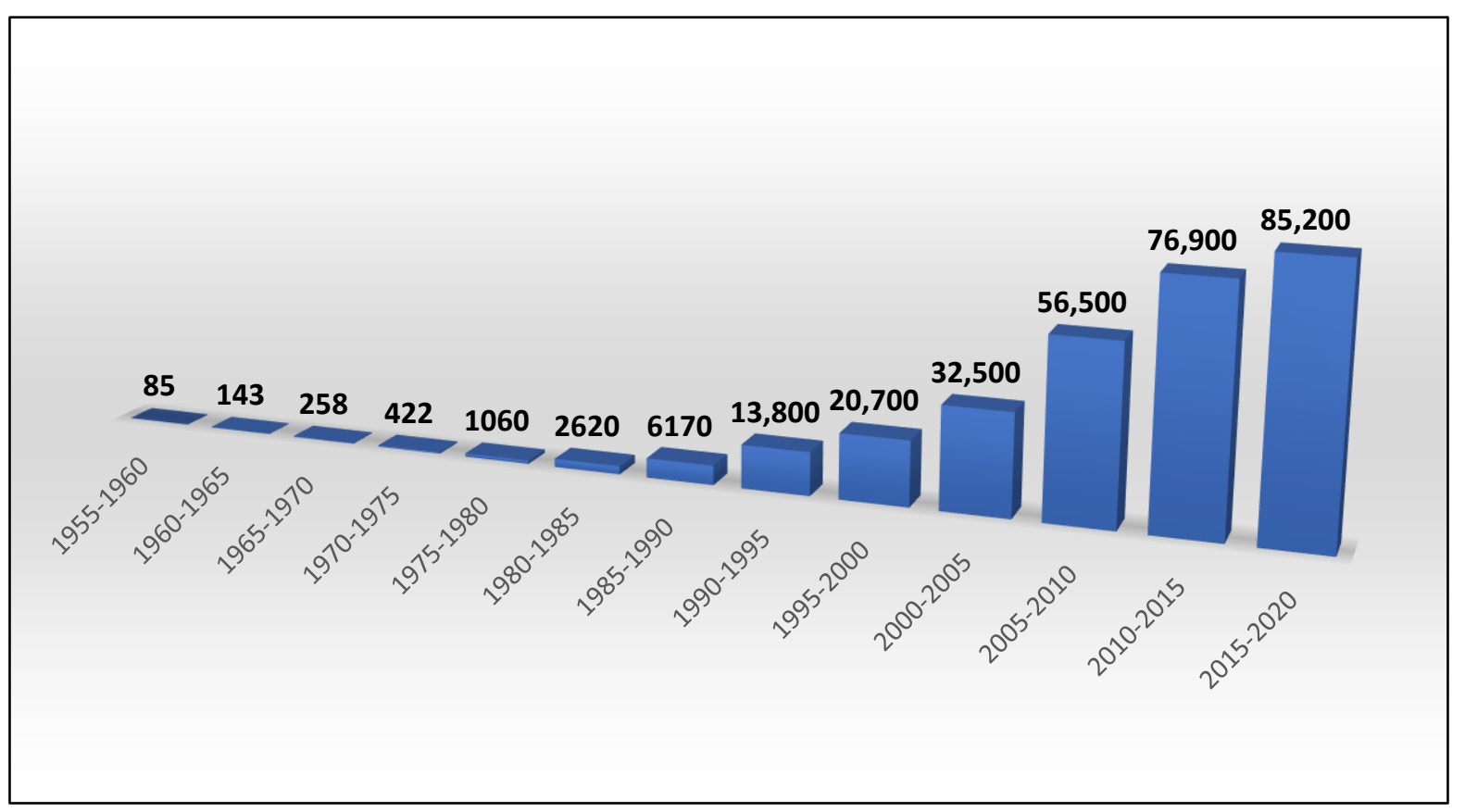

Figure 1. The trend of CD publications from 1955 to 2020, obtained using the keyword "cyclodextrin" from Google Scholar (http:/ / scholar.google.com (accessed on 6 December 2021)).

Since 1975, publications regarding CDs, modified CDs, and their application have steadily increased to the present day (Figure 1) $[2,6,9,10]$, with several impactful papers about CDs only recently (See for example [22-28]). Much of this increase is due to more cost-effective, industrial CD production [29-34].

In this review, we introduce the fundamental structural and chemical properties of CDs. In particular, we discuss the origin and the role of CD conformational flexibility in complexation (i.e., encapsulation, see Section 2). We also discuss several factors that influence CD complexation (Section 3), citing several examples from the scientific literature. Later in the review (Section 4), we briefly discuss some main applications of CDs, which include textiles [10,35], foods [36,37], cosmetics [38], solar energy [39], and environmental applications $[40,41]$. All of these combined set this review apart from other reviews written on the subject because comparatively few reviews discuss these in this order and in such great detail. We hope that readers will gain an appreciation of the value of CDs in scientific research, in industry, and even, in everyday life.

\section{Structural and Chemical Properties of Cyclodextrins}

The wide range of novel applications of CDs is mainly due to their unique structural properties. Thus, to understand their versatility and applicability, it is essential to begin with a description of their physicochemical properties. 


\subsection{The Shape of the Native Cyclodextrins}

Cyclodextrins (CDs) are non-toxic [6], sugar polymers that are stable in water and some organic solvents $[4,6]$. They show high stability under alkaline conditions; the reported pKa values of the natural CDs range from 12.1 and 13.5 [42]. Thus, at low $\mathrm{pH}$, CDs are susceptible to acid hydrolysis, which results in ring opening, subsequently causing the formation of various linear oligosaccharides and glucose units [43]. CDs are nonreducing, cyclic oligosaccharides consisting of a series of $\alpha$-D-glucopyranose subunits joined by $\alpha-1,4$-glycosidic bonds. Geometrically, CDs are distinguished by their hydrophilic circular truncated cone shape. This cone shape has a hydrophobic, hollow conical cavity of $7.9 \AA$ depth. This cavity is suitable for the inclusion of appropriately sized hydrophobic guest molecules [4,44-47].

The three native cyclodextrins, alpha $C D(\alpha-C D)$, beta $C D(\beta-C D)$, and gamma $C D$ $(\gamma-\mathrm{CD})$, have six, seven, and eight D-glucose subunits, respectively [6], and their structures are shown in Figure 2. The D-glucose subunit typically assumes a ${ }^{4} \mathrm{C}_{1}$ chair conformation (Figure 3), and sometimes, though less frequently, the ${ }^{1} \mathrm{C}_{4}$ chair conformation [48-52]. The chair conformation of the D-glucose subunit overall $C D$ angular strain. It also puts the "bulky" oxygen groups (hydroxyls, glycosidic groups) into the equatorial plane [53], further stabilizing the CD molecule.
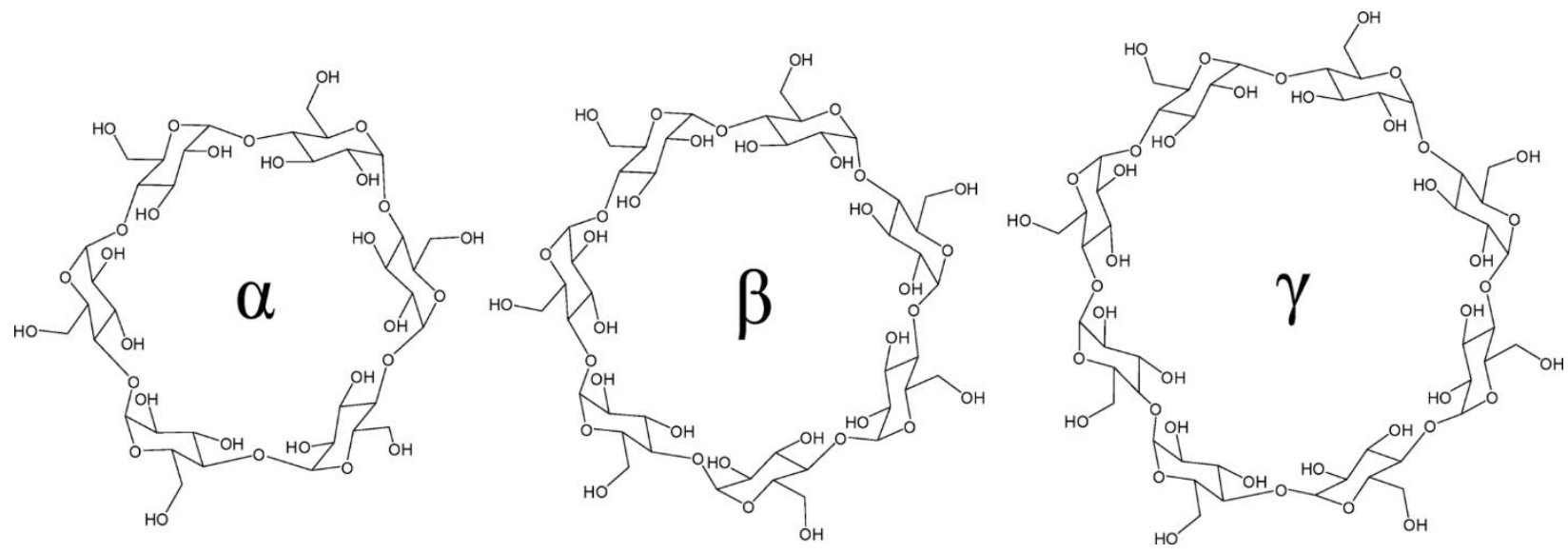

Figure 2. Structures of the three native cyclodextrins. Reprinted with permission from [54]. Copyright 2009 American Chemical Society.

The chair conformation of the D-glucose subunit has another structural impact; it causes the three native cyclodextrins to form a "truncated" cone $[55,56]$ instead of a straight symmetrical cylinder, as shown in Figure 4.

The formation of the truncated cone causes the free hydroxyl groups to change their orientation. The hydroxyl groups point towards the outside of the cyclodextrin molecule, with the $\mathrm{C} 2$ and $\mathrm{C} 3-\mathrm{OH}$ groups pointing towards the wide rim, and $\mathrm{C} 6-\mathrm{OH}$ groups pointing towards the narrow rim [42] (Figure 5). This exterior lining of hydroxyl groups allows CDs to form hydrogen bonds with water molecules; thus, CDs have some aqueous solubility. The aqueous solubility properties of CDs are discussed more in Section 2.4.

Unlike the polar exterior of CDs, the interior cavity is hydrophobic. The cavity is hydrophobic because it is is lined with non-polar groups-C3, O4 glycosidic bond (etherlike), and $\mathrm{C} 5-\mathrm{CH}$ (aliphatic-like) groups [57] (Figure 6). The hydrophobic cavity has the ability to encapsulate, either partially or fully, small organic molecules [47]. This encapsulation ability has proven useful for applications in medicine, industry, food, textiles, cosmetics, etc., some of which are discussed in Section 4. 


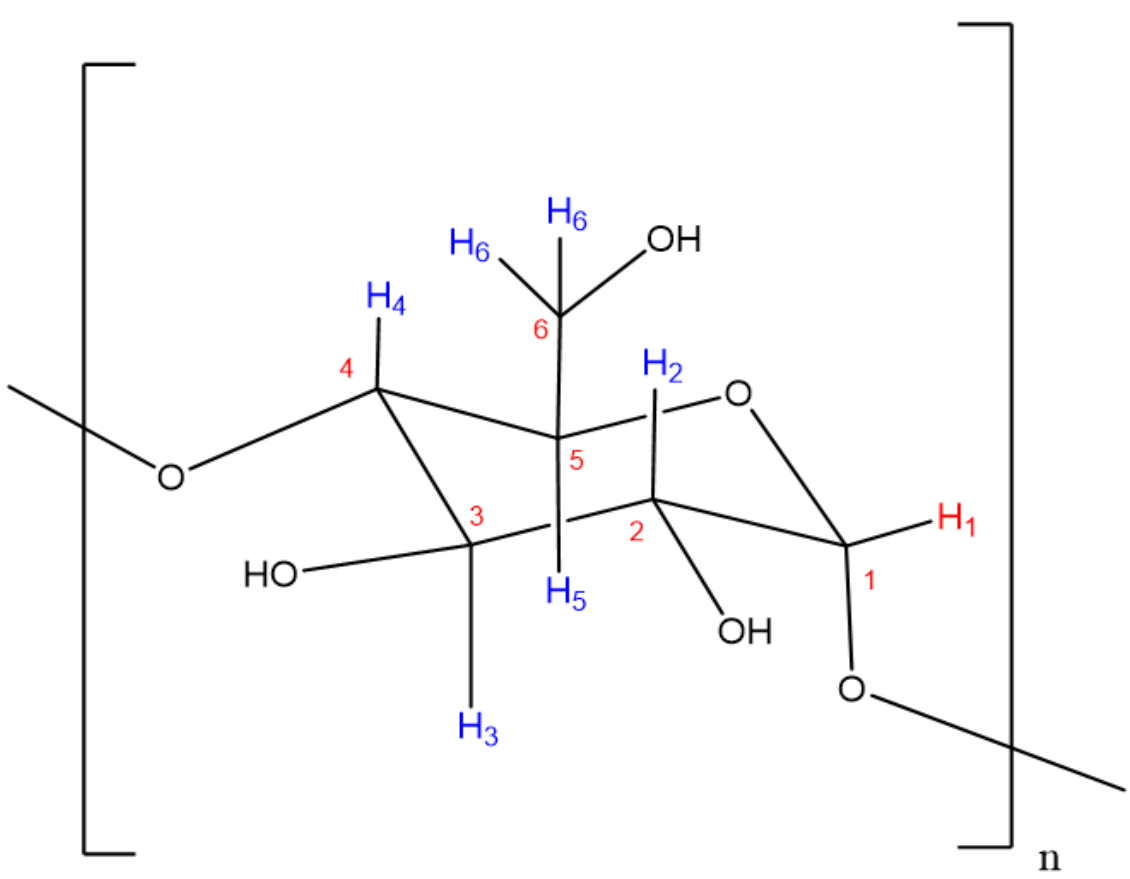

Figure 3. Structure of the glucose unit in cyclodextrins. The D-glucose unit shown here is the ${ }^{4} \mathrm{C}_{1}$ conformation with the $\alpha-1 \rightarrow 4$ glycosidic bond. (C stands for "chair", and the numbers represent the position of carbon atoms that are above and below the rest of the carbons, respectively [55].) Carbon atoms are numbered in red, and hydrogens (excluding hydroxyl hydrogens) groups are marked in blue. $n=6,7$, and 8 , for $\alpha-C D, \beta-C D$, and $\gamma-C D$, respectively. Figure created in ChemDraw 18.1.
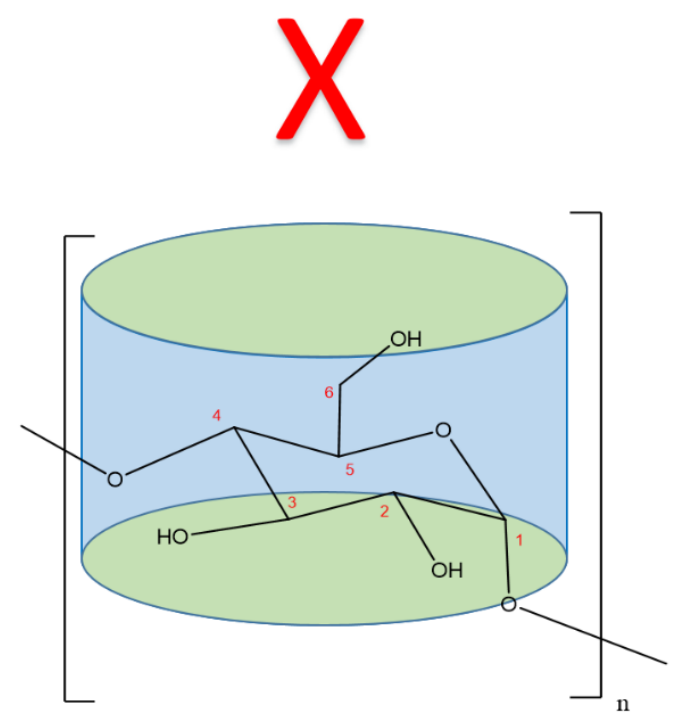

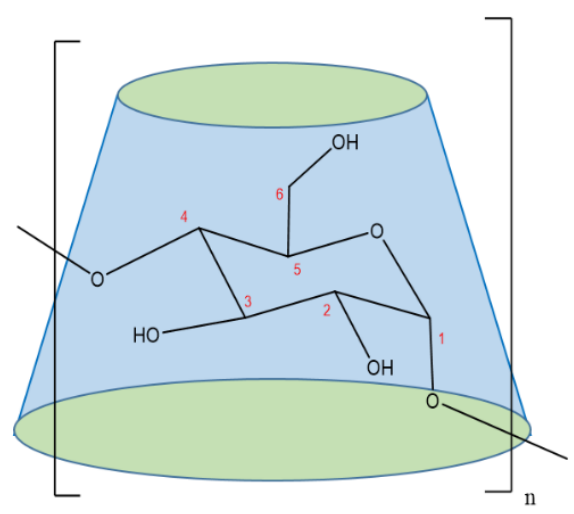

Figure 4. The three native CDs, $\alpha-C D, \beta-C D$, and $\gamma-C D$, form a truncated cone (right) instead of the symmetrical cone (left). $n=6,7$, and 8 , for $\alpha-C D, \beta-C D$, and $\gamma-C D$, respectively. Figure created in ChemDraw 18.1. 


\section{Primary}

Hydroxyls on

C6 pointing towards the narrow rim.
Hydrophobic cavity

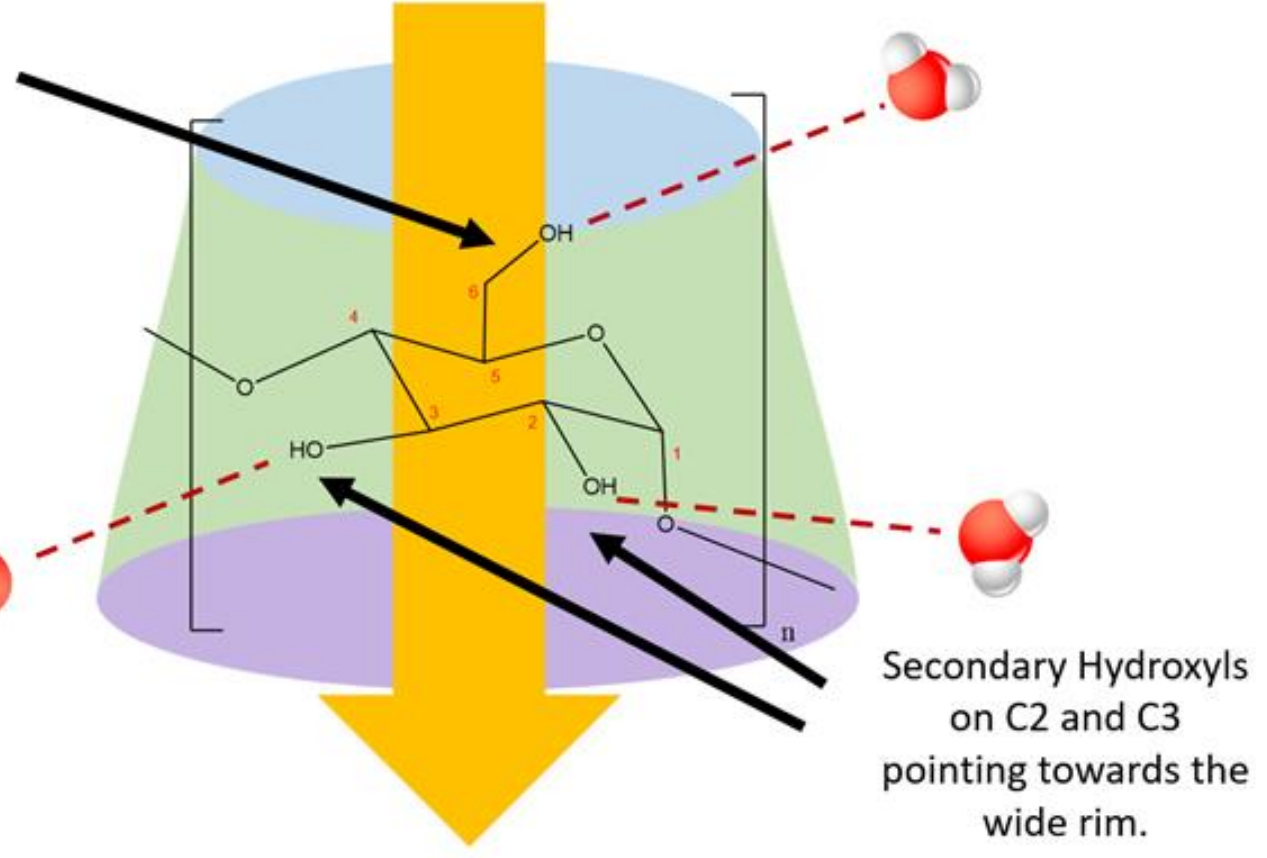

Figure 5. Primary and secondary hydroxyls point towards the outside of the cyclodextrin molecule. Figure created with the aid of ChemDraw 18.1.

\section{C3 carbons}

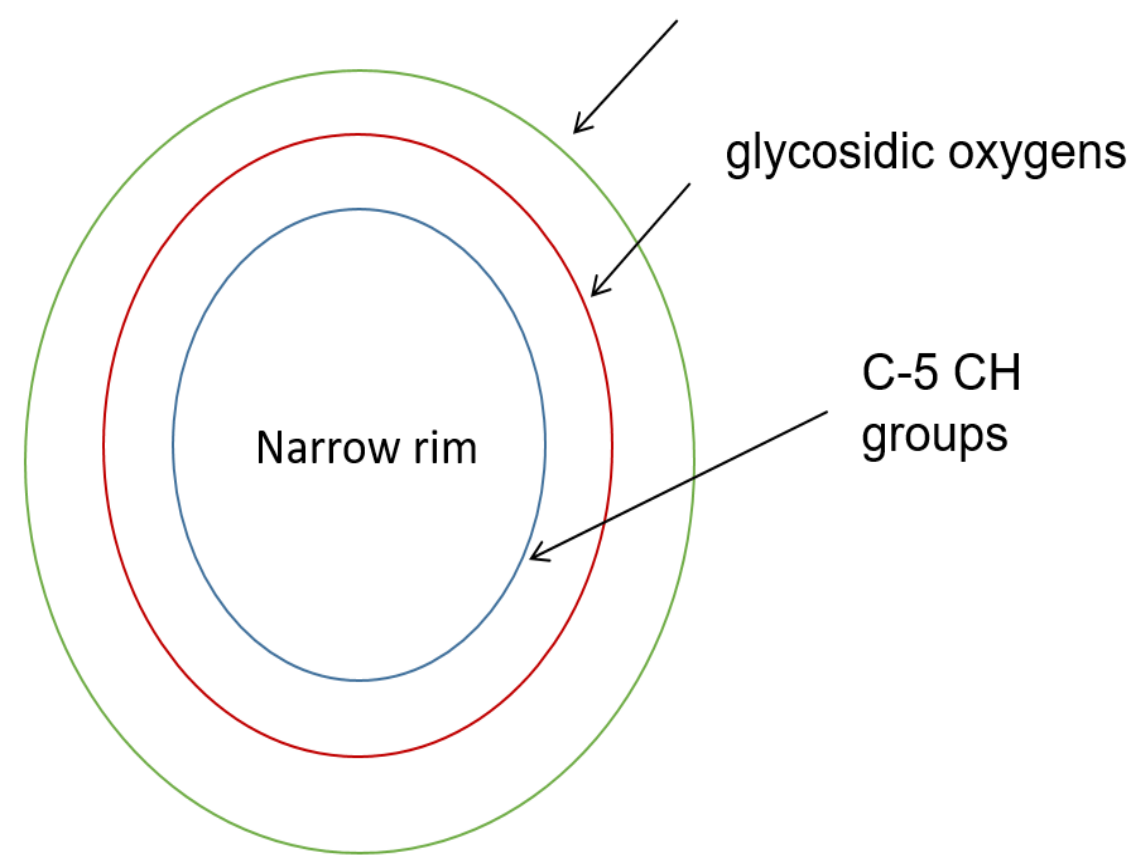

\section{Wide rim}

Figure 6. Interior lining of $\alpha-C D, \beta-C D$, and $\gamma-C D$.

\subsection{Cyclodextrin Size Properties and Overall Flexibility}

The hydrophobic cavities of the $\alpha-C D, \beta-C D$, and $\gamma-C D$ vary in size, and increase from the smallest $C D(\alpha-C D)$ to the largest $(\gamma-C D)$, reflecting that the three native $C D$ s have 
different numbers of glucose units [20]. The size properties of $\alpha-C D, \beta-C D$, and $\gamma-C D$ are listed in Table 1, and are illustrated in Figure 7. Note that in Table 1 and Figure 7, the inner diameter lengths are listed as a range instead of a single number. Frequently, the scientific literature reports the inner cavity diameter as a single number [6,58-60], although a range is also reported sometimes [61,62]. Reporting the inner cavity diameters as a range is more appropriate, as it reflects the inherent flexibility present in CDs.

Table 1. Select dimensions for $\alpha-C D, \beta-C D$, and $\gamma-C D$.

\begin{tabular}{|c|c|c|c|c|c|c|}
\hline Cyclodextrin & $\begin{array}{l}\text { No. of Glucose } \\
\text { Units }\end{array}$ & $\begin{array}{l}\text { Molecular } \\
\text { Weight }\end{array}$ & $\begin{array}{c}\text { Cavity } \\
\text { Diameter }(\AA)^{a}\end{array}$ & $\begin{array}{c}\text { Outer } \\
\text { Diameter }(\AA ̊)\end{array}$ & Height $(\AA ̊)$ & $\begin{array}{c}\text { Cavity Volume } \\
\left(\AA^{3}\right)^{d}\end{array}$ \\
\hline$\alpha$ & 6 & 972 & $4.7-5.2$ & 14.6 & 7.8 & 174 \\
\hline$\beta$ & 7 & 1135 & $6.0-6.4$ & 15.4 & 7.8 & 262 \\
\hline$\gamma$ & 8 & 1297 & $7.5-8.3$ & 17.5 & 7.8 & 427 \\
\hline
\end{tabular}

${ }^{a}$ From [62]. ${ }^{b}$ From $[9,63] .{ }^{c}$ From [64]. ${ }^{d}$ From [65].

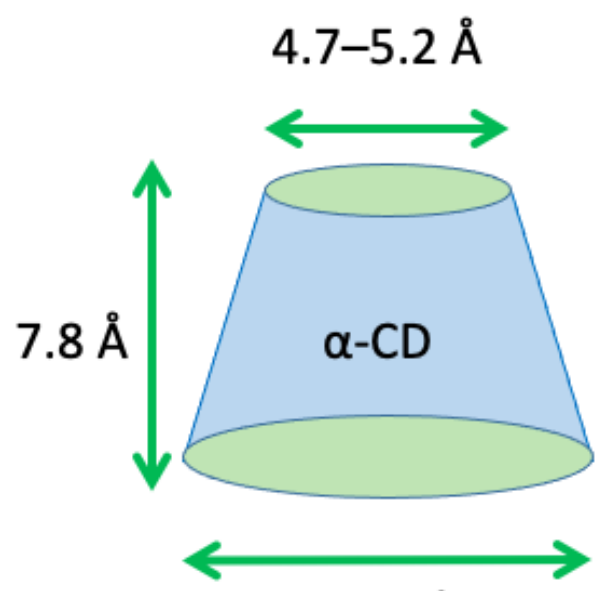

$14.6 \AA$

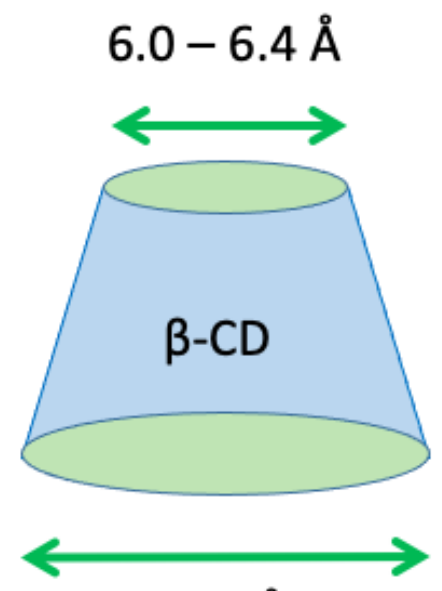

$15.4 \AA$

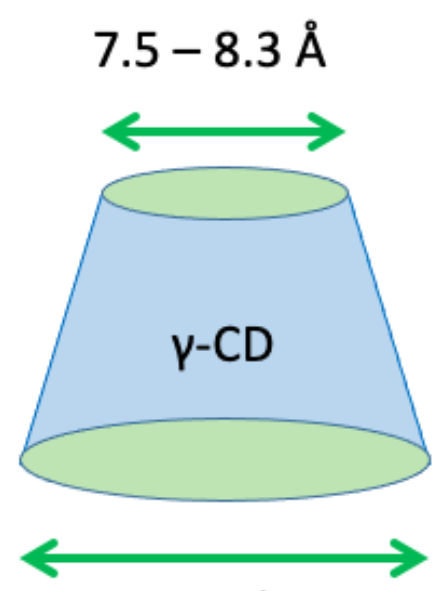

$17.5 \AA$

Figure 7. Dimensions (height, inner cavity diameter, outer diameter) of $\alpha-C D, \beta-C D$, and $\gamma-C D$.

The glucose subunit has been reported as "rigid" [51,62], therefore making the entire subunit "rigid". This argument is supported by X-ray crystallography studies, which first elucidated the structure of the CD molecule [66-68], and which enabled researchers to discover the truncated cone shape [2]. The X-ray crystallography technique, however, is limited to solid state samples; therefore, it alone does not suffice to solidify the claim that CDs are rigid molecules, and it alone cannot explain why CDs form stable complexes with many types of molecules $[9,19,59,69-76]$. Therefore, other analytical techniques are required to substantiate the conclusion that CDs are rigid molecules.

For example, Vibrational Raman Optical Activity [77] and Nuclear Magnetic Resonance (NMR) Spectroscopy [78-82] have proven that CDs have considerable conformational flexibility [83]. Recent studies that exclude X-ray crystallography also support this [84-86]. Several molecular dynamics studies account for CD conformational flexibility, providing valuable structural insights for CD molecules [87-90]. Hence, it is incomplete to claim CDs are "rigid", and therefore, it is more appropriate to report the inner cavity diameter as a range rather than a single number.

Larger cyclodextrins containing up to 31 glucose units have been studied and characterized [51,52,91-95], and their conformational flexibility is considerably larger than those of their smaller counterparts ( $\alpha-C D, \beta-C D$, and $\gamma-C D)$ [52]. However, this increased flexibility decreases their overall stability, and severely limits their ability to form complexes like $\alpha-C D, \beta-C D$, and $\gamma-C D$ [52]. For this reason, larger cyclodextrins (beyond $\gamma-C D)$ are beyond the scope of this review. 


\subsection{The Torsion Angle Index}

Generally speaking, the glucose subunit in CDs retains the ${ }^{1} C_{4}$ or ${ }^{4} C_{1}$ chair conformation, even when another molecule is inside the hydrophobic cavity $[51,95]$. This allows CD overall stability, and the ability to maintain the truncated cone shape [62]. This is partly due to limited internal rotation within the glucose unit [96]. However, there are three characteristic bonds with considerable rotational flexibility [51,89,97], the C5-C6 bond, and the two torsion angles, $\phi$ and $\psi$, which are defined as the angles between $\mathrm{O} 4 \bullet \bullet \bullet C 1-\mathrm{O} 4{ }^{\prime}-\mathrm{C} 4$, and $\mathrm{C} 1-\mathrm{O} 4{ }^{\prime}-\mathrm{C}^{\prime} \bullet \bullet \bullet \mathrm{O} 4$ "'; respectively, where the prime and double primed atoms belong to directly adjacent glucose subunits [98]. The rotatability of these angles is reported in Figure 8, with representative values for $\phi$ and $\psi$ listed in Table 2.

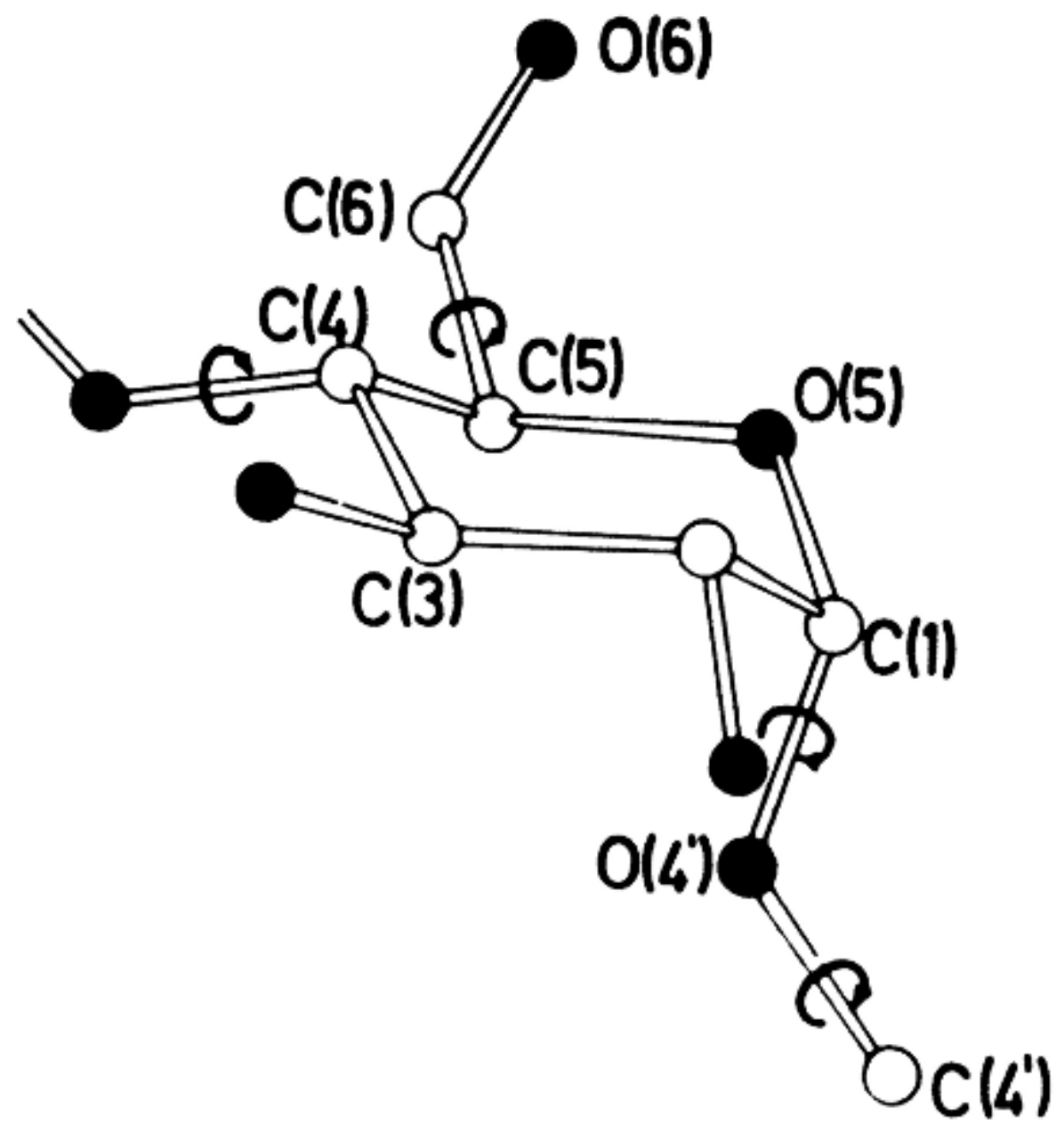

Figure 8. Visual representation of rotatable bonds (marked in black circles with a single arrowhead) in CDs. Reprinted with permission from [51]. Copyright 1998 American Chemical Society.

Table 2. Representative angle values for rotatable bonds in CDs. Reprinted with permission from [98].

\begin{tabular}{ccc}
\hline Cyclodextrin & $\boldsymbol{\phi ( { } ^ { \circ } )}$ & $\boldsymbol{\Psi}\left({ }^{\circ}\right)$ \\
\hline$\alpha$ & 166 & -169 \\
$\beta$ & 169 & -172 \\
$\gamma$ & 165 & -169 \\
\hline
\end{tabular}

The C5-C6 bond involves the exterior primary hydroxyl groups [98,99], and does not contribute much to CD overall flexibility. However, the rotatable torsional angles of CDs are on the inside, and analyzing the properties of these two angles $(\varphi, \psi)$ provides valuable structural insights about CDs. 
Using molecular dynamics, Sandilya et al. (2021) [89] studied the structure of the native CDs, and found that even though the outside of the CD is a truncated cone, the inner cavity takes the form of a conical hourglass, as shown in Figure 9. This hourglass shape occurs because glycosidic oxygens protrude inwards [89], which in turn is possible because of flexibility about the glycosidic bond $(\varphi, \psi)$. Similarly, Naidoo et al. (2008) [97] examined the structure of the native CDs using molecular dynamics, and found that the range of angle values for $\varphi$ (defined as $\mathrm{H}^{\prime}-\mathrm{C1}^{\prime}-\mathrm{O} 4-\mathrm{C} 4$, prime denotes an adjacent glucose subunit) torsion rotations is limited as compared with $\psi$ (defined as $\mathrm{C1}^{\prime}-\mathrm{O} 4-\mathrm{C} 4-\mathrm{H} 4$ ) rotations for each $\alpha-C D, \beta-C D$, and $\gamma-C D$. From observing this and other molecular parameters, Naidoo et al. (2008) concluded that the $\psi$ torsion angle (i.e., the glycosidic bond) is the main cause for CD glucose subunits tilting inwards or outwards [97], again confirming that CDs have conformational flexibility.

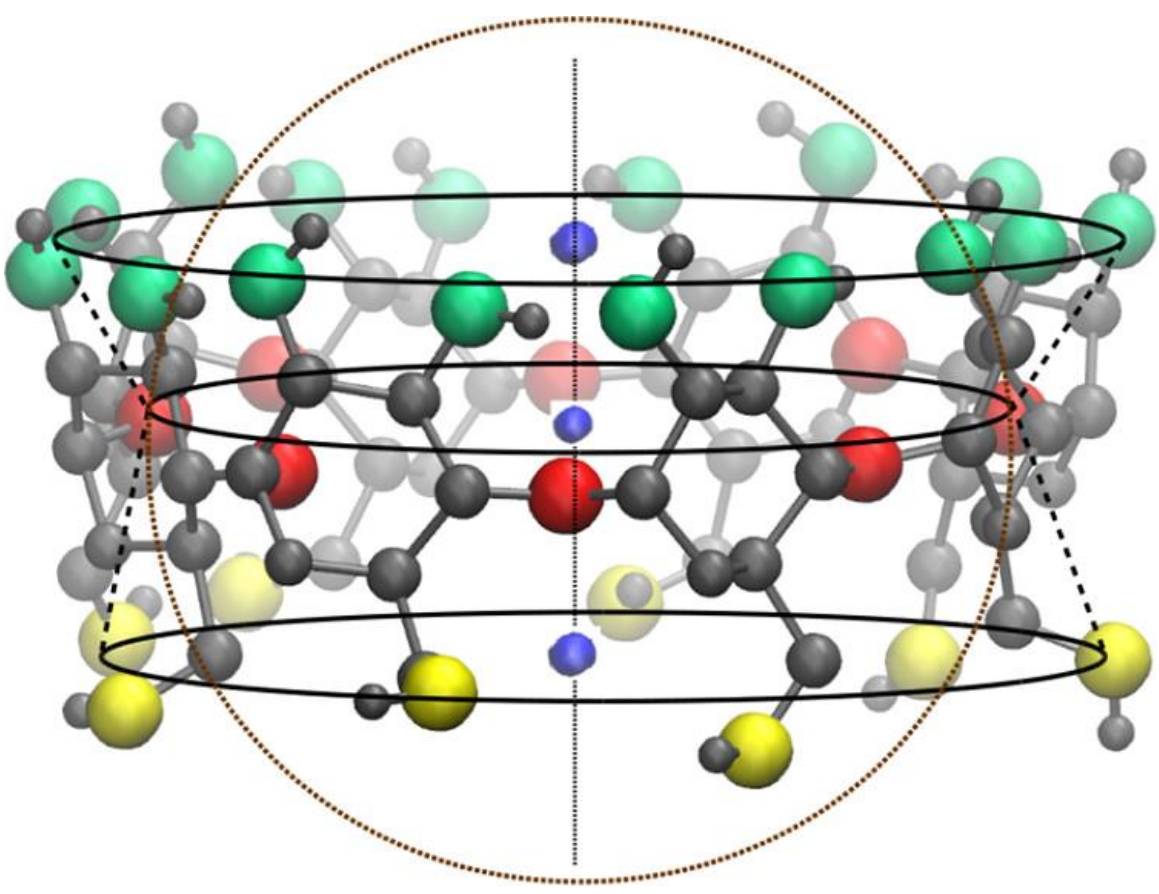

Figure 9. Hourglass form of the internal cavity, represented by solid and dashed black lines. Red spheres represent $\mathrm{O} 1$ atoms, green spheres represent $\mathrm{O} 2$ and $\mathrm{O} 3$ atoms, yellow spheres represent $\mathrm{O} 6$ atoms, and gray spheres represent carbon atoms. Hydrogen atoms are omitted for clarity. Reprinted with permission from [89]. Copyright 2020 American Chemical Society.

These theoretical studies are experimentally validated $[77,83]$. Tafazzoli and Ghiasi (2009) found a relationship between the chemical shift of the anomeric carbon of the native CDs, and the angles $\varphi$ and $\psi$ using molecular dynamics. This relationship strongly correlates with results from NMR experiments [100]. Previously, it was proven that the NMR chemical shift of the anomeric proton (H1) and ${ }^{13} \mathrm{C}$ NMR of cyclodextrins depends on the conformation of the torsion angles (glycosidic bonds) [101]. Futhermore, Sandilya et al. (2020) [89] and Naidoo et al. (2008) [97] also validated their theoretical studies with NMR experiments, showing that the torsion angles play a key role in CD conformational flexibility.

\subsection{Hydrogen Bonding and Cyclodextrin Aqueous Solubility}

As stated earlier, CDs are lined with primary and secondary hydroxyl groups. These hydroxyl groups can hydrogen bond with water molecules and other polar chemicals. The number of hydrogen bond donors/acceptors for each $\alpha-C D, \beta-C D$, and $\gamma-C D$ is quite large [42], and is listed in Table 3. The large number of hydrogen bond donors and acceptors results in a large, negative $\log \mathrm{P}_{\mathrm{o} / \mathrm{w}}$ [42], which is the logarithmic value of the octanol/water partition coefficient [102]. 
Table 3. Hydrogen bonding capacity of and $\operatorname{LogPo} / \mathrm{w}$ values of the native CDs.

\begin{tabular}{cccc}
\hline Property & $\alpha$-CD & $\beta-C D$ & $\gamma$-CD \\
\hline LogP calculated & -12.7 & -14.82 & -16.93 \\
Acceptor count calculated & 30 & 35 & 40 \\
Donor count calculated & 18 & 21 & 24 \\
\hline
\end{tabular}

Despite a comparable number of hydrogen bond donors and acceptors, $\alpha-C D, \beta-C D$, and $\gamma-C D$, the aqueous solubility of each differs drastically from the other two. The maximum amount of cyclodextrin that can be dissolved at $25^{\circ} \mathrm{C}$ and $1 \mathrm{~atm}$ are $14.5,1.85$ and $23.2 \mathrm{~g}$ in $100 \mathrm{~mL}$ of water for a $\alpha-C D, \beta-C D$, and $\gamma-C D$, respectively [103]. This trend remains the same even at higher temperatures (Table 4) [103].

Table 4. Water solubility of the three native cyclodextrins *. Data taken from [103].

\begin{tabular}{cccc}
\hline Temperature $\left({ }^{\circ} \mathbf{C}\right)$ & $\alpha$-CD & $\beta$-CD & $\gamma$-CD \\
\hline 25 & 12.8 & 1.8 & 25.6 \\
45 & 29.0 & 4.5 & 58.5 \\
60 & 66.2 & 9.1 & 129.2 \\
\hline
\end{tabular}
${ }^{*} \mathrm{~g} / 100 \mathrm{~mL}$.

One would expect the aqueous solubility of $\beta-C D$ to be somewhere in between that of $\alpha-C D$ and $\gamma-C D$, and yet, $\beta-C D$ has the lowest aqueous solubility. Despite this anomalous solubility, $\beta-C D$ and its derivatives are the most used for drug studies due to its aptly sized inner cavity $[71,104]$. Some researchers believe that the anomalous solubility of $\beta-C D$ may be attributed to its molecular rigidity [105]. Specifically, the C2 and C3 secondary hydroxyl groups in $\beta-C D$ form hydrogen bonds between each other, creating an inflexible, yet complete secondary belt. This complete "belt" limits the ability of $\beta-C D$ to form hydrogen bonds with surrounding water molecules [4]. On the contrary, both $\alpha$-CD and $\gamma$-CD possess higher aqueous solubility than does $\beta-C D$ due to an incomplete belt of hydrogen bonds and a non-coplanar structure, respectively [42].

The low aqueous solubility of CDs presents a major challenge for industrial and pharmaceutical application. To overcome this obstacle, the CD hydroxyl groups (the secondary and/or primary) can be chemically modified. Using this creative approach also improves the aqueous solubility of organic drugs in CDs, thus increasing the applicability and versatility of CDs $[9,73,74,106-108]$.

For example, the aqueous solubility of $\beta-C D$ increases to $>1200 \mathrm{mg} / \mathrm{mL}$ ( $>80$-fold increase from $18.5 \mathrm{mg} / \mathrm{mL}$ ) when the 2-hydroxy group is replaced with a 2-hydroxypropyl group to become 2-hydroxypropyl $\beta$-CD (HP- $\beta C D$ ) [47]. Albendazole and fenbendazole, two imidazole based drugs used to treat alveolar echinococcosi [109], had tremendously different aqueous solubilities upon complexation with $\beta-C D$ and HP $\beta-C D$ [110] (See Table 5). From Table 5, it is clearly seen that introducing chemical modifications can tremendously affect drug solubility in water.

Table 5. Comparsion of Albendazole and Fenbendazole Aqueous Solubtility when complexed with $\beta-C D$ and HP $\beta-C D$. Datak taken from [110].

\begin{tabular}{ccc}
\hline CD Used & $\begin{array}{c}\text { Albendazole Aqueous } \\
\text { Solubility }(\mu \mathbf{g} / \mathbf{m L})\end{array}$ & $\begin{array}{c}\text { Fendendazole Aqeuous } \\
\text { Solubility }(\mu \mathrm{g} / \mathbf{m L})\end{array}$ \\
\hline- & 0.4188 & 0.1054 \\
\hline$\beta-C D$ & 93.47 & 45.56 \\
\hline $\mathrm{HP} \beta-\mathrm{CD}$ & 443.06 & 159.36 \\
\hline
\end{tabular}

Even with the aid of chemical modifications, the modest aqueous solubility of the native CDs still warrants further investigation, as understanding the interactions of the 
native CDs with water molecules may yield crucial structural information [89]. This information can be utilized to improve drug/CD complexation. This knowledge is of utmost importance, especially when it comes to pharmaceutical applications, where CDs are used to mitigate the bioavailability problems of drugs resulting from poor aqueous solubility, poor stability, and severe side effects [34,111-114].

\subsection{Cyclodextrin Derivatives}

CDs can be modified by substituting various functional groups on the primary and/or the secondary face of the molecule. This substitution could occur to any glucosyl residue, and the ligands need not be attached to the same glucose unit. Modified CDs have found uses in pharmaceuticals, foods, and separations. Through modification, the chemical and physical properties of cyclodextrins can be improved for various applications such as enzyme mimicry [115-117], and for the catalysis of the reactions of molecules held within the cavity [118]. Modified CD catalysis is novel since the substitution groups initiate a reaction with the substrate bound molecule. This enhances reaction rate and reaction yield by 1000-fold and 4-fold, respectively [115].

Another interesting property of modified CDs is their chelating ability, which has been exploited in pharmaceuticals for use as delivery systems [119], increased drug bioavailability [120], and increased drug activity.

Moreover, modified CDs have been used to control the release of food constituents. In particular, modified CDs have been used to remove bitter components from aqueous solution to control the release of fragrances, to stabilize liquids, and to mask odors, tastes, and colors [121].

Interestingly, modified CDs are used in gas and liquid chromatography. For example, Schmarr et al. (1991) [122] found that dilution of the modifie CD stationary phase with other stationary phases in gas chromatography diluted the chiral selectivity of the modified CD.

The use of modified CDs will probably increase due to the low cost of cyclodextrin synthesis and their widerange of applications, from anti-HIV activity [123] to food stabilization [124], and to enzyme mimicry [116].

\section{Complexation Properties of Cyclodextrins}

\subsection{Introduction}

CDs can form complexes with a wide range of molecules, including alkyl glycosides [125-127], chiral compounds [128-133], branched or cyclic alkyl groups [134,135], aromatic molecules [130,136,137], and proteins [138-141]. Interactions between cyclodextrins (host) and guest molecules may yield a stable complex with a high equilibrium constant; for example, $\beta-C D$ forms a highly stable inclusion complexes with adamantyl derivatives with a binding constant of $\sim 10^{4}-10^{5} \mathrm{M}^{-1}[142,143]$ (See Table 6 for more examples). A typical complexation process is illustrated in Figure 10.

Table 6. CD inclusion complexes with high binding constants. (Errors on binding constnats not provided for cliarity).

\begin{tabular}{cccc}
\hline Guest & Host & Binding Constant $\left.\mathbf{( M}^{-\mathbf{1}}\right)$ & Reference \\
\hline Ketoprofen & $\gamma$-CD & $2.351 \times 10^{3}$ & {$[144]$} \\
\hline Ascorbic acid & $\beta-\mathrm{CD}$ & $3.655 \times 10^{3}$ & {$[104]$} \\
\hline $\begin{array}{c}\mathrm{B}_{12} \mathrm{I}_{12}{ }^{2-} \\
\text { (dodecaborate cluster) }\end{array}$ & $\gamma$-CD & $6.7 \times 10^{5}$ & {$[145]$} \\
\hline 9-triamantane carboxylic acid & $\gamma$-CD & $5.0 \times 10^{5}$ & {$[146]$} \\
\hline
\end{tabular}




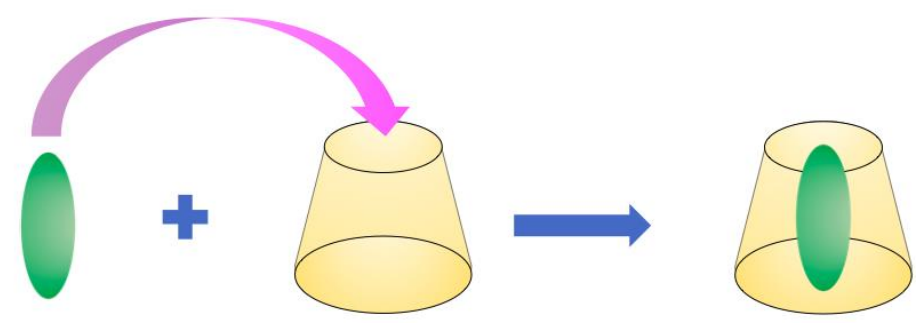

Figure 10. A standard mechanism for CD complexation. Here, the guest molecule (green) approaches the empty CD cavity (orange). Once the guest molecule is inside the CD cavity, either partially of completely, complexation is complete.

CDs form various types of complexes [147], depending on the number of $\mathrm{CD}(\mathrm{s})$ and/or guest molecule(s) [57]. These types of complexes are classified based on the ratio of CD to guest; the 1:1 complex formation is by far the most common [42], but other types (1:2, 2:1, 2:2, 3:1, etc.) have been reported. This also affects binding kinetics, and the calculation of binding constants from biophysical data [57]. Regarding CDs, complexation is mainly enthalpy drive, and disfavors entropy $[148,149]$.

Several factors contribute to complexation formation. A few of these factors are listed in Table 7. We present each factor listed in Table 7 in detail below, citing several examples of how each factor influences the $\mathrm{CD}$ complexation process.

Table 7. Factors affecting CD-complexation formation.

Size and shape of the CD cavity

$\mathrm{CD} / \mathrm{CD}$-complex self-assembly or aggregation

Chemical properties of guest molecule(s)

Expulsion of "high-energy" water molecules (applies to aqueous solutions only)

\subsection{Size and Shape of the Cyclodextrin Cavity}

As noted above (see Table 1) $\alpha-C D, \beta-C D$, and $\gamma$-CD have similarly sized hydrophobic cavities. Despite this similarity, this one factor significantly affects $\mathrm{CD}$ complex formation. Just like the story of Goldilocks and the three bears, there is one sized cavity that "fits just right" for the particular application [150].

For example, Szente et al. (2018) [151] examined how the different sizes of three native CDs and some of their derivatives affect cell cytotoxicity and cholesterol homeostasis. They found that $\beta$-CD has a greater impact on cell (HEK293T, TZM-bl, Jurkat, and HeLa) viability than either $\alpha-C D$ or $\gamma-C D$, indicating that the size of the CD cavity affects its cytotoxic activity [151]. Cholesterol has poor aqueous solubility, with reported solubility values ranging from $25-29 \mathrm{ng} / \mathrm{mL}$ [152]. Some $\beta$-CD derivatives, (Heptakis 2, 6-di-Omethyl) $-\beta-C D$ with $95 \%$ purity, randomly methylated $\beta-C D$, and Hydroxypropyl- $\beta-C D$ ) increased the solubility of cholesterol from $25-29 \mathrm{ng} / \mathrm{mL}$ to $4.56,4.97$, and $0.75 \mathrm{mg} / \mathrm{mL}$, respectively. The $\gamma$-CD derivative (hydroxypropyl- $\gamma-\mathrm{CD}$ ) did not solubilize cholesterol at all. This suggests that $\beta-C D$ has an increased ability to bind cholesterol than does $\gamma-C D$, probably due to the more aptly sized $\beta-C D$ cavity [151]. These results are consistent with earlier studies $[153,154]$ and show that CD cavity size directly influences CD molecular binding capacity.

Another study also demonstrates the effect of $\mathrm{CD}$ cavity size on molecular binding. Yang et al. (2009) [155] studied the complexation of $\alpha-C D, \beta-C D$, and $\gamma-C D$ and a few CD derivatives with scutellarin using UV-Vis and NMR. Scutellarin, a flavonoid drug, formed complexes with $\alpha-\mathrm{CD}, \beta-\mathrm{CD}, \mathrm{HP} \beta-\mathrm{CD}$, and $\gamma-\mathrm{CD}$ with different binding strengths. At $\mathrm{pH}=7.20$ and $25.0^{\circ} \mathrm{C}$, the binding constants $\left(\mathrm{K}_{\mathrm{S}}, \mathrm{M}^{-1}\right)$ of scutellarin to HP- $\beta-\mathrm{CD}$, $\beta-C D$, and $\alpha-C D$ were 1925,634 , and 210, respectively. Spectral changes were too small to accurately calculate the binding constant of scutellarin to $\gamma-C D$, meaning that the binding of scutellarin to $\gamma-C D$ was weak [155]. The values of these numbers suggest that the HP- $\beta-C D$ 
and $\beta-C D$ have the optimal binding size, whereas the cavity of $\alpha-C D$ is too small, and $\gamma-C D$ is too large. Based on these results, this study strongly indicates a relationship between CD cavity size and molecular binding.

One final example firmly supports an effect of the CD cavity on CD complex formation. In their study of quinine shape adaptation in $\alpha-C D, \beta-C D$, and $\gamma-C D$, Wójcik et al. (2019) [156] demonstrated via NMR studies, that quinine binds best to $\beta-C D\left(1516 \mathrm{M}^{-1}\right)$, followed by $\alpha-\mathrm{CD}\left(379 \mathrm{M}^{-1}\right)$ and $\gamma-\mathrm{CD}\left(344 \mathrm{M}^{-1}\right)$ at $\mathrm{pH}=10.5$, and $\mathrm{T}=25^{\circ} \mathrm{C}$. These different binding strengths alone demonstrate that CD cavity size influences CD complex formation, and as such, validate the results of Szente et al. (2018) [151] and Yang et al. (2009) [155]. Therefore, the size of the CD cavity strongly influences molecular binding strength.

\subsection{Self-Assembly and Aggregation of Cyclodextrins and Their Complexes}

The native CDs and their complexes form cage-like or channel-like structures [51,157,158]. Cage type structures can be further broken down into "herringbone" and "brick wall" [51] structures, and channel type can further be broken down into different orientations (headto-head, or head-to-tail) $[159,160]$. For the reader's convenience, these structures and their categories are diagrammed in Figure 11. The self-assembly and aggregation of cyclodextrins and their complexes in solution may either increase or inhibit the formation of complexes, depending on the experimental conditions. CD aggregation may also distort the true binding constant of the guest molecule [161].

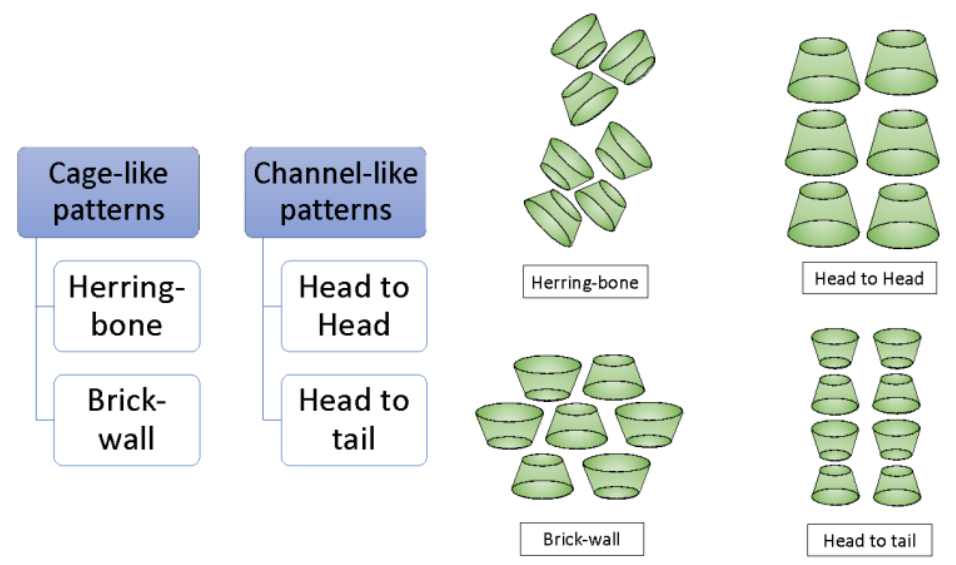

Figure 11. Standard aggregation categories and structures of CD and CD complexes. Adapted from [157,162] with permission. Ref. [157] by CC 3.0, and [162] by Copyright 2004 American Chemical Society.

Differential light scattering (DLS) [163], NMR [164,165], circular dichroism [161], and several types of microscopy [166] have been used to measure CD aggregation and its effect on complexation formation. Despite available methods and resources, the mechanism of CD aggregation is still poorly understood, and experimental evidence shows seemingly contradictory results [157]. Part of the arising contradiction results from the inherent limitations of the experimental techniques used. For example, circular dichroism is sensitive to the turbidity of a solution, and is therefore extremely sensitive to CD aggregation [167], which may cause turbidity in the solution [168]. However, DLS and electron transmission microscopy have given reliable results pertaining to CD aggregation [157].

Despite an incomplete understanding regarding this subject., there are some generally accepted facts. These include an increase in aggregate size at increased CD concentration [166], and that aggregates of native CDs appear at concentrations (3-12 mM) well below their aqueous solubility limits (See Table 4). Furthermore, the critical aggregation concentrations (below which aggregation cannot occur) of $\alpha-C D, \beta-C D$, and $\gamma-C D$ are reported at $25 \mathrm{mg} / \mathrm{mL}(26 \mathrm{mM}), 8 \mathrm{mg} / \mathrm{mL}(7 \mathrm{mM})$ and $9 \mathrm{mg} / \mathrm{mL}(7 \mathrm{mM})$, respectively [169]. 
Aggregation of CDs with Small Molecules

It is essential to consider the influence of $\mathrm{CD}$ aggregation on molecular binding, since it can and in some cases does, affect binding strength. Bikádi et al. (2006) [170] considered this influence as they relate CDs binding to carotenoids. In their study, the authors found that the aggregation properties of $C D$ derivatives significantly influenced their complexation behavior with carotenoids, and pigments found in fruits, vegetables, plants, and photosynthetic bacteria [171,172]. Of the CD derivatives studied, randomly methylated $\beta-C D$ had the lowest tendency to aggregate, and the highest binding affinity to carotenoids. Bikádi et al. (2006) further revealed, based on results from molecular modeling experiments, that the lower the self-aggregation of CDs, the better their binding affinities with carotenoids [170].

Likewise, Huang et al. (2019) [173] investigated the effects of CD aggregation on the binding of glipizide to $C D s(\beta-C D, \gamma-C D, H P-\beta-C D$, Me- $\beta-C D)$. Glipizide/CD aggregation was observed for each of the four CDs, especially at higher concentrations. However, altering the structure of the $C D$ (i.e., $\beta-C D$ to Me- $\beta-C D$ or HP- $\beta-C D$ ) significantly altered the tendency of the glipizide/CD complex to aggregate. The glipizide/Me- $\beta-C D$ complex had the strongest binding affinity of the four different complexes considered, presumably because the glipizide/Me- $\beta-\mathrm{CD}$ complex aggregated the least [173]. Thus, The study supports, at least in part, the hypothesis that increased $C D$ aggregation leads to decreased molecular binding.

It seems reasonable to extend this hypothesis (i.e., less $C D$ aggregation equals more binding) to other types of $\mathrm{CD} /$ small molecule complexes. However, each host-guest system must be considered individually, as individual cases could prove to be exceptions to this "rule". A couple of individual cases are explored below.

For example, Chun et al. (2012) [174] measured the diffusion rate eugenol through $\beta-C D$ to determine the extent of CD complex aggregation. These authors induced eugenol/ $\beta-C D$ complexation by shaking mixtures of eugenol and $\beta-C D$ for several hours; they observed that larger aggregate particles $(1110 \mathrm{~nm})$ formed at longer shaking times $(24 \mathrm{~h})$ than those particles $(650 \mathrm{~nm})$ formed at shorter shaking times $(8 \mathrm{~h})$. The diffusion rate of the larger aggregated particles (eugenol/ $\beta-C D$ complex) was lower than that of the smaller aggregated particles, indicating that aggregation of the eugenol $/ \beta-C D$ complex hindered the release of eugenol from the $\beta$-CD cavity [174]. While this study does not directly support the above mentioned hypothesis (i.e., the diffusion rate is not necessarily correlated with binding affinity), it does demonstrate that the effect of $\mathrm{CD}$ aggregation on $\mathrm{CD}$ complexation cannot simply be ignored, and deserves some consideration and analysis.

Similarly, Jo et al. (2015) [175] investigated the relationship between the concentrations of trans-cinnamaldehyde and $\beta-C D$ and trans-cinnamaldehyde $/ \beta-C D$ aggregation. Not surprisingly, increased concentrations of both components induced more aggregation and formation of larger particles. However, $\beta-C D$ encapsulation was higher than $90 \%$, and $\beta-C D$ had a high retention ( $>80 \%$ ) of trans-cinnamaldehyde at higher $\beta-C D$ concentrations due to increased aggregation of the trans-cinnamaldehyde/ $\beta$-CD complex [175]. This work presents seemingly contradictory results, and so, it cannot be simply stated that less CD aggregation results in stronger binding.

Guest molecules can also influence $\mathrm{CD}$ aggregation. For example, in pure aqueous solution, $\gamma$-CD has a critical aggregation concentration of 4.2\% $(w / v)$ [176]. Rodrigues Sá Couto et al. (2019) [176] found that when carbamazepine, a drug used in the treatment of epilepsy [177], is present in the solution, the critical aggregation concentration of $\gamma-C D$ drops to $2.5 \%(w / v)[176]$.

Additional studies show the influence of $\mathrm{CD}$ aggregation or $\mathrm{CD} /$ small molecule aggregation on CD complexation [176-180], but the results of these studies do not reveal a clear trend between $C D$ aggregation and $C D$ complexation. Some fundamental issues remain to be addressed $[157,181]$, thus demonstrating the need for additional studies. Additional studies in this area should shed light on the $\mathrm{CD} /$ complexation process, and will prove useful for drug delivery, since many of the small molecules studied in CD complexes 
are drugs, and aggregation will likely affect the ability of CDs to effectively bind to and/or release drugs.

\subsection{Chemical Properties of the Guest Molecule}

The chemical properties of the guest molecule, strongly influences the binding strength of the $\mathrm{CD} /$ molecule complex. A few of these properties include their charge (i.e., neutral, cationic, anionic), the types of intermolecular interactions (i.e., hydrogen bonding, van der Waals, dipole-dipole) involved, and the size/shape of the guest molecule. The contribution of each of these factors to $\mathrm{CD}$ complexation varies depending on the class/type of guest molecules. Therefore, while it may be said that while one factor tends to dominate or influence binding of CDs to molecules, it is rash to say that this factor and its level of contribution is absolute. Nonetheless, each of these factors (i.e., ionic charge, intermolecular interactions, guest molecule size/shape) plays an important role, and we consider each of them in the following sections.

\section{Ionic Charge of the Guest Molecule}

The interior cavity of the native CDs is hydrophobic [182], and its polarity is similar to that of n-octanol for pyrene [183]. The internal polarity of $\beta-C D$ is reported to be similar to that of ethanol [184]. As such, the CD interior cavity interacts best with molecules that possess van der Waals/hydrophobic types of intermolecular interactions [185-187]. Therefore, it is expected that non-polar, neutrally charged organic molecules of appropriate shape and size, possessing van der Waals/hydrophobic type interactions, will bind best to the $\mathrm{CD}$ cavity, and this is generally the case. Van der Waals/hydrophobic interactions are considered one of the most important forces in CD complexation formation [6,188].

However, the presence of a charge on organic molecules can significantly affect the orientation of guest molecules in the CD cavity, and the stability of CD complexes [189]. The discussion that follows will address these changes, and is not intended as a comprehensive description of the effect of charge on $\mathrm{CD}$ complexes; it serves only to demonstrate that the charge of a molecule must be considered in CD complexation formation. Table 8 is provided to facilitate a comparative analysis of the studies discussed in this section.

Table 8. Comparison of Different Studies exploring ionic charge and its effect on CD complexation.

\begin{tabular}{|c|c|c|c|c|}
\hline Guest & Host (s) & $\begin{array}{c}\text { Type of Charge (i.e., } \\
\text { Positive and/or Negative) }\end{array}$ & Effect on CD Binding & Ref. \\
\hline Adamantane derivatives & $\begin{array}{c}\beta-C D, D M-\beta-C D \\
\text { TM- } \beta-C D\end{array}$ & Positive, Negative & $\begin{array}{l}\text { Positively charged end } \\
\text { of guests pointed out } \\
\text { the wide rim, negative } \\
\text { charge had no effect }\end{array}$ & [190] \\
\hline Trifluoperazine & $\begin{array}{c}\beta-C D, D M-\beta-C D \\
H P-\beta-C D\end{array}$ & $\begin{array}{l}\text { Less positive (i.e., more } \\
\text { negative) }\end{array}$ & Stronger binding & [191] \\
\hline Imatinib & $\beta-C D$ & $0,+1,+2$, and +3 & $\begin{array}{l}\text { Weakest binding at }+1 \text {, } \\
\text { strongest binding at }+3\end{array}$ & [192] \\
\hline $\begin{array}{c}p \text {-nitrophenol, } \\
\text { p-nitrophenolate }\end{array}$ & $\alpha-C D, \beta-C D$ & $\begin{array}{c}0 \text { (p-nitrophenol }) \\
-1(p \text {-nitrophenolate })\end{array}$ & $\begin{array}{l}\text { Anionic guest bound } \\
\text { more strongly }\end{array}$ & {$[193,194]$} \\
\hline $\begin{array}{c}\text { Some carboxylic acids and } \\
\text { their conjugate bases }\end{array}$ & $\alpha-C D$ & $\begin{array}{c}0 \text { (carboxylic acids) } \\
-1 \text { (conjugate bases) }\end{array}$ & Negligible effect & [195] \\
\hline $\begin{array}{c}\text { nitrobenzene, } \\
\text { carboxybenzene, benzoate, } \\
\text { 4-nitrophenol, } \\
\text { 4-nitrophenolate }\end{array}$ & $\alpha-C D$ & $\begin{array}{c}0 \text { (nitrobenzene) } \\
0 \text { (carboxybenzene) } \\
-1 \text { (benzoate) } \\
0 \text { (4-nitrophenol) } \\
-1 \text { (4-nitrophenolate) }\end{array}$ & Negligible effect & [196] \\
\hline
\end{tabular}


An ionic charge can alter guest orientation in the CD cavity. For example, adamantane derivatives with positively charged groups have their positively charged group sticking out from the wider end of $\beta-C D$ and its derivatives (DM- $\beta-C D$, and TM- $\beta-C D$ ). Negatively charged adamantane derivatives show no preference for the orientation within the CD cavity; the negatively charged groups simultaneously protrude from the narrow end or the wider end of the cavity in the same sample (though not within individual CD/adamantane derivative complex molecules) [190].

Additional studies demonstrate change in CD binding strength due to a (positively) charged molecule. Some guest molecules bind to CDs better when they have a lower positive charge. For example, the $\mathrm{pH}$ (i.e., charge) of the solution changes the binding strength of trifluoperazine, an organic molecule, to $\beta-C D, D M-\beta-C D$, and HP- $\beta-C D$. Trifluoperazine exhibits higher binding constants to these $\mathrm{CDs}$ at higher $\mathrm{pH}$ values (i.e., more basic $=$ less positive) [191]. This trend is also observed in the binding of 7-hydroxyflavone in $\beta-C D$ [197], and in the binding of quinine to $\alpha-C D, \beta-C D$, and $\gamma-C D$ [156].

Béni et al. (2007) [192], however, found an unusual exception to this trend (less positive = better binding). Imatinib, a tyrosine kinase inhibitor (also known as Gleevec) [198], has three protonatable sites, and thus, four possible charged forms $-0,+1,+2$, and +3 . When interacting with RAMEB (Randomly Methylated $\beta-C D)$, the stability constant, $\operatorname{LogK}$, decreased with each successive increase in charge, with a minimum value at +3 , meaning that imatinib bound weakest at higher levels of positive charge, following the trend recently mentioned. When binding to $\beta-C D$, however, imatinib surprisingly had the lowest LogK value at charge $=+1$, and higher $\operatorname{LogK}$ values at charge $=+2$ and at charge $=+3$ [192] .

The binding of cyclodextrins to anionic (negatively charged) organic compounds sometimes show an opposite trend to that of cationic compounds (i.e., negative charge increases binding). Sometimes, anionic compounds bind even better to CDs than their corresponding neutral components [188,199-201], particularly due to charge transfer (see Figure 12).

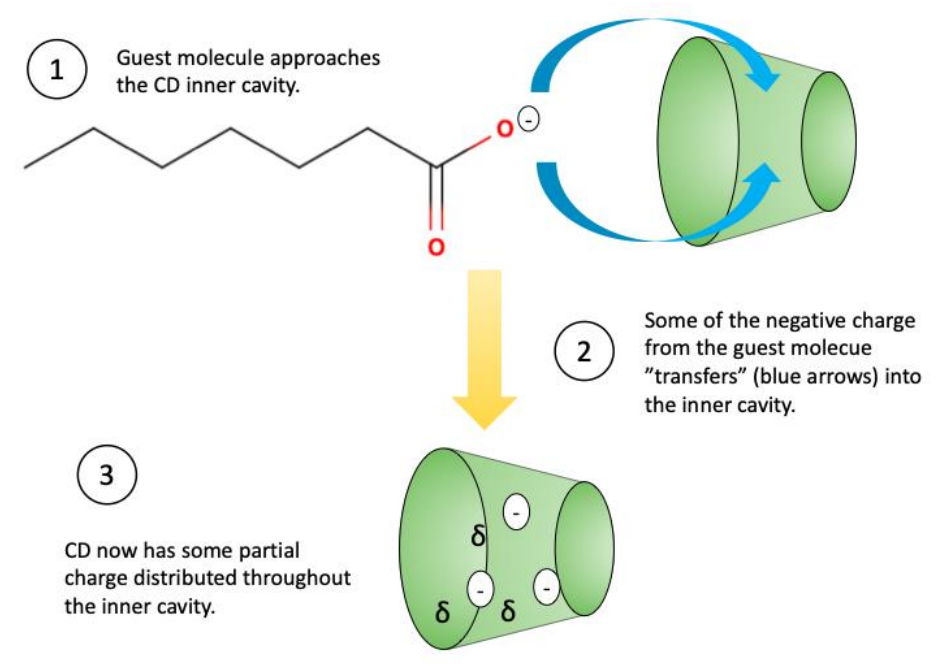

Figure 12. Illustration of charge transfer between a hypothetical guest molecule (heptanoate) and a CD. Heptanoate created using ChemDraw 18.1.

Perhaps the most commonly cited example is the comparison of the binding of p-nitrophenol, and its conjugate base, p-nitrophenolate, to CDs [193,194]. The reported binding constants of p-nitrophenol and p-nitrophenolate to $\beta-C D$ as are $130 \mathrm{dm}^{3} \mathrm{~mol}^{-1}$ and $410 \mathrm{dm}^{3} \mathrm{~mol}^{-1}$, respectively, a nearly threefold increase from neutral compound to anionic compound [193]. The average binding constants of p-nitrophenol and $p$-nitrophenolate to $\alpha$-CD are reported at $248 \mathrm{M}^{-1}$ and $2507 \mathrm{M}^{-1}$, respectively, a nearly fivefold increase [194]. Both papers $[193,194]$ indicate that the rationale for this increase in binding constant is charge transfer between guest ( $p$-nitrophenolate) and host ( $\beta-C D$ or $\alpha-C D)$ via electron resonance, meaning that the $p$-nitrophenolate donates some of its electron density to the CD 
cavity. The protonated form, $p$-nitrophenol can perform this same type of resonance, but to a lesser extent, and so, cannot undergo charge transfer as efficiently as p-nitrophenolate.

Jiménez and Alderete (2005) [195] also investigated charge transfer in their study of 30 carboxylic acids and their conjugate bases binding to $\alpha$-CD. They found that charge transfer does not necessarily increase the binding of the carboxylate base as compared to the its conjugate acid; density functional theory (DFT) models, however, support the fact that charge transfer between carboxylate anions and $\alpha-C D$ contributes to the formation of stable complexes [195]. This study shows that charge transfer between anionic guest and host may serve to stabilize the $\mathrm{CD}$ /anionic compound complex, even if charge transfer does not increase binding strength.

In addition, charge transfer does not necessarily dominate in CD/anionic complexes. For example, when $\alpha$-CD forms complexes with nitrobenzene, carboxybenzene, benzoate, 4-nitrophenol, or 4-nitrophenolate., charge transfer only contributes $\sim 6 \%$ of guest-host binding energy, a very small amount. Nevertheless, the guest molecules (nitrobenzene, carboxybenzene, benzoate, 4-nitrophenol, and 4-nitrophenolate) decreased the dipole moment of $\alpha-C D$ by an average of $9 \%$, thus affecting the association between the guest and host molecules [196]. Hence, it is essential to consider the role of charge transfer/distribution in the binding process of anionic/CD complexes, even if it is not the main contributing force in anionic/CD complexation formation.

\subsection{Intermolecular Forces between Guest and Host}

The guest molecule must possess the "correct" organic functional groups for optimal binding to the cyclodextrin cavity. Since the CD cavity is hydrophobic, it is most likely to bind to organic molecules with hydrophobic (van der Waals) types of interactions, and less likely to bind well to molecules possessing hydrophilic (i.e., polar) organic functional groups.

\subsubsection{The Dominating Van Der Waals Forces in CD Complexation}

In most cases, van der Waals forces are the principal interactions that stabilize CD-guest complexes. For example, Cai et al. (2006) [202] observed that the binding energies of the acyl groups of phospholipids (palmitoyloleoylphatidylinositol, palmitoyloleoylphatidylserine, and palmitoyloleoylphatidylethanolamine) to $\alpha-C D$ were much lower than the binding energies of the phospholipid head groups. The acyl groups almost exclusively contain van der Waals forces, leading to the conclusion that van der Waals forces are the driving force of phospholipid complexation with $\alpha$-CD [202]. Similarly, Du et al. (2020) [203] concluded that the main binding force between $\beta-C D$ and geranyl acetone, a compound commonly used as a flavoring agent [204,205], is mainly a van der Waals force. In addition, Wang et al. (2009) [206] found that van der Waals forces were a main driving force in the complexation of Litsea cubeba essential oil with $\beta-C D$ and a few of its derivatives (DM- $\beta-C D, H E-\beta-C D$, and $\mathrm{HP}-\beta-\mathrm{CD})$.

Other types of intermolecular forces influence CD-complexation; however, van der Waals forces seem to remain the priority force for determining inclusion complex stability. $\beta-C D$ For example, complexation of $\beta-C D$ with select sunscreen agents (oxybenzone, octocrylene, and ethylhexyl-methoxycinnamate) was driven by a combination of different forces. These included electrostatic, van der Waals, bond angle bending, and dihedral angle bending forces. Despite the presence of all there the van der Waals force which contributed to $90 \%$ or more of the total binding energy of sunscreen agent to $\beta-C D$ [207]. This study, and others like it, demonstrate the dominating effect of van der Waals forces on guest molecule binding to CDs.

\subsubsection{Hydrogen Bonding between Guest and Host}

Hydrogen bonding is the most relevant polar intermolecular force for cyclodextrins in solution, as the native cyclodextrins do not possess ionizable groups (except in extremely acidic or basic environments). 
The hydrogen bonding capacity of the exterior hydroxyl groups of native CDs is limited, especially that of $\beta-C D$, due to a strong network of intramolecular hydrogen bonds (see Section 2.4) [4]. The inner cavity of CDs has zero capacity to form hydrogen bonds with guests, as it does not possess hydrogen donors or acceptors (i.e., a hydroxyl group). Generally speaking, hydrogen bonding plays a minor role in CD complex stabilization [208]. Also, at higher temperatures, the effect of hydrogen bonding on $\beta$-CD complex stabilization tends to decrease, while the effect of van der Waals forces remains about the same [209].

Hydrogen bonding does, however, contribute to overall CD complexation formation and stability [208], and sometimes acts in tandem with Van der Waals forces to stabilize CD complexes. For example, Li et al. (2005) [210] proposed that both van der Waals forces and hydrogen bonding are responsible for the encapsulation of chloramphenicol, a ribosometargeting antibiotic [211] by $\beta-C D$, based upon the calculated thermodynamic parameters determined for the binding of chloramphenicol to $\beta$-CD [210]. Furthermore, Audino et al. (2005) [212] attributed the stability of the 1:1 Methoprene/ $\beta-C D$ to van der Waals forces and hydrogen bonding.

As with other driving forces for $\mathrm{CD}$ complexation, the role of hydrogen bonding in $\mathrm{CD}$ complexation remains elusive. Further studies aimed at understanding these roles could prove useful for certain types of drugs and CD complexes.

\subsubsection{Release of High Energy Water Molecules and Their Role in Complexation}

In both liquid and solid states, the cavities of CDs usually contain a certain number of water molecules. There is currently no consensus on the "exact" number of water molecules the CD cavity may contain [189]. A single $\beta$-CD molecule, for example, is reported to have 10-12 water molecules [213]. In addition, multiple hydrates are possible for each native CD. For example, Connors (1997) reported two hydrate forms for $\alpha-C D$, one with 6 water molecules, and the other with 7.57 water molecules [57]. In the same paper, the author listed two hydrate forms for $\beta-C D$, one with 11 water molecules, and the other with 12 water molecules [57]. These differences in reported numbers are not unexpected. As discussed earlier (see Section 2.2), CD have conformational flexibility [57], not molecular rigidity, otherwise their ability to form inclusion complexes would be severely limited [47,51,83,84].

A water molecule associating with the hydrophobic groups of the CD cavity loses approximately two hydrogen bonds, and is energetically frustrated [89]. As such, the water molecules inside the cavity are high energy (enthalpy rich) [56,214,215]. The "driving out" of these high-energy water molecules (process outlined in Figure 13) is a key driving force in CD complexation in aqueous solutions [6,188]. Thus, it is important to understand the interactions between water molecules and the components of the CD complex [216,217]. 


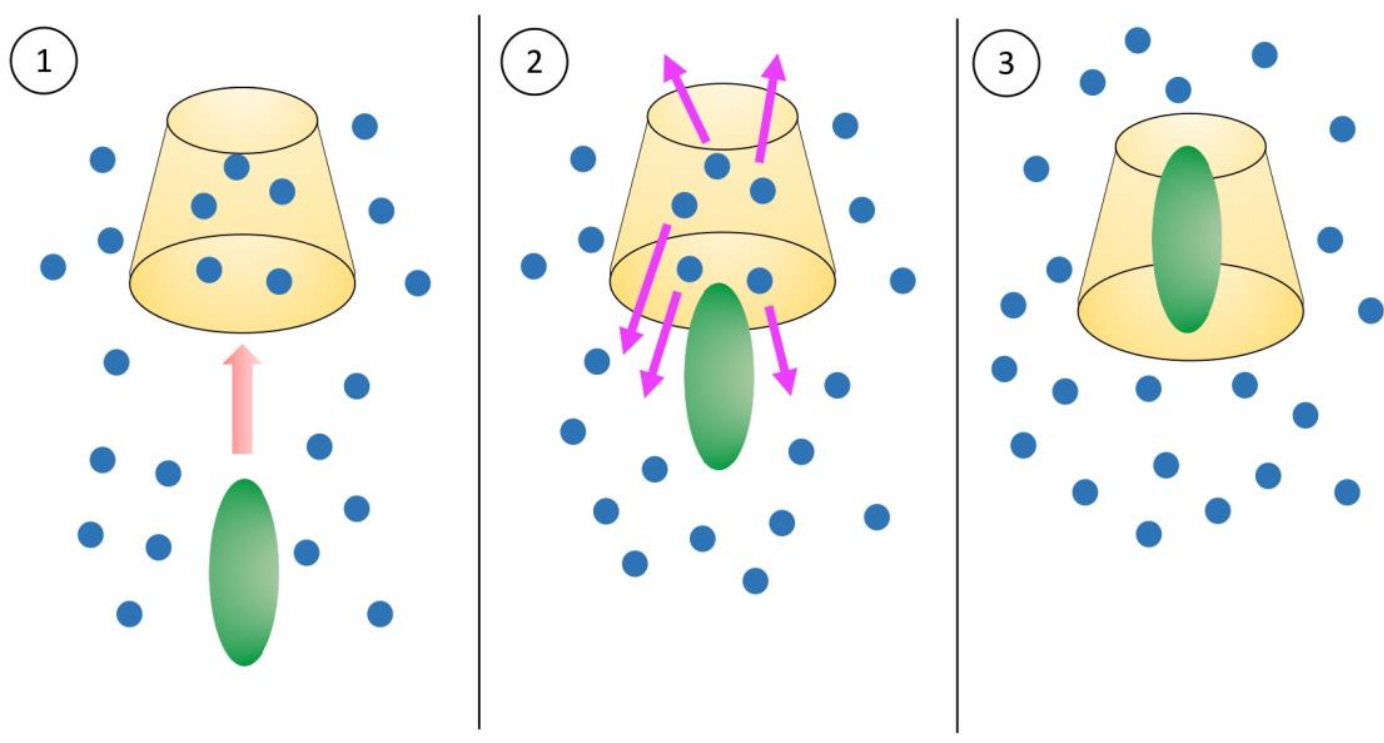

Figure 13. Outline the process of water expulsion from the CD cavity as a complex is formed. The process is as follows: (1) guest molecule approaches CD cavity, (2) the hydrophobic portion of the guest molecule begins to "expel" the water molecules from the CD cavity to bulk solution, (3) a complex is formed, and the water molecules inside the CD cavity originally are now in the bulk solution. The green oval represents the guest molecule, the orange cone the CD host, and the blue circles water molecules.

The first study to seek to understand the role of high energy water release in $\mathrm{CD}$ complexation involved the interactions between d-limonene, a major constituent in citrus oils [218], and $\alpha-C D, \beta-C D$, and $\gamma-C D$ [219]. The authors of this study found that the minimum number of molecules required for $\mathrm{d}$-limonene complexation with $\alpha-C D, \beta-C D$, and $\gamma-\mathrm{CD}$ is 2,7 , and 12 , respectively. The estimated number of released water molecules was 4,7 , and 8 for $\alpha-C D, \beta-C D$, and $\gamma-C D$, respectively. These results were determined using the auto-catalytic inclusion model, and were comparable to those obtained by crystal analysis [219]. These imply that water inclusion and exclusion, are necessary for d-limonene to bind to the $\mathrm{CD}$ cavity, demonstrating the powerful role water molecules play in $\mathrm{CD}$ complexation (in aqueous solution).

An earlier paper than the one previously discussed [219] examined the effect of water and ethanol of d-limonene/CD complexation [220]. Using the micro-aqueous method, the authors determined that a minimum number of water molecules was required for d-limonene to complex with $\alpha-C D, \beta-C D$, or $\gamma-C D$. Ethanol was also found to contribute, in part, to the d-limonene/CD complexation, acting as a type of "space regulator" between d-limonene and the CD cavity [220]. Thus, this study demonstrates that water molecules are in part responsible for the complexation between d-limonene and CDs.

A more recent example serves to emphasize the role of high-energy water molecules in CD complexation in aqueous solution; García-Río et al. (2010) showed that water release from the $\mathrm{CD}$ cavity plays a definitive role in the complexation of meta- and parasubstituted benzoyl chlorides by DM- $\beta-C D$ [221]. The meta substituents of the benzoyl chlorides $\left(3-\mathrm{CF}_{3}, 3-\mathrm{Cl}\right)$ showed increased formation constants at increased temperatures. The para substituents of the benzoyl chlorides $\left(4-\mathrm{NO}_{2}, 4-\mathrm{MeO}\right)$, however, showed decreased formation constants with increased temperatures. The same authors ascribe this difference in thermodynamic behavior to the difference in the number of water molecules excluded from the DM- $\beta-C D$ cavity. The more closely the guest molecule (benzoyl chloride) fits into the cavity, the more water molecules will be released from the cavity. Since the 1:1CD/meta substituents complexes have higher binding constants as compared to the 1:1 complexes of the para substituents, the meta substituents fit more neatly into the DM- $\beta-C D$ cavity, and hence, drive out more water molecules [221]. Thus, the driving out of water molecules 
constitutes an essential driving force for the complexation of benzoyl chloride substituents. This argument could easily extend to other types of organic molecules complexing with $\mathrm{CD}$ cavities in aqueous solution.

Water molecule expulsion from the CD cavity plays a pivotal role in $\mathrm{CD}$ complexation in aqueous solution. Water molecules also form stabilizing interactions with CD-drug complexes in the solid state [221,222], but these interactions do not necessarily indicate the exclusion of water molecules from the cavity.

The interactions between water molecules and the components of $\mathrm{CD}$ complexes is a fascinating area of physical chemistry research, and future efforts to elucidate the causes and factors behind these interactions will yield important structural insights for CD complexation, which in turn can be used in important applications such as pharmaceuticals (i.e., drug/CD complexes).

\section{Applications of Cyclodextrins}

Due to CDs biodegradability, biocompatibility, and versatility, their industrial applications are very varied. The applications discussed here (Section 4) are outlined in Figure 14. CDs have been used in the textile and pharmaceutical industries, as well as in agriculture, food technology, for environmental protection, chemical and biological analysis, and in dyes and cosmetics. Many of these applications are possible because of the ability of CDs to form stable complexes with many types of molecules. This will be emphasized throughout the remainder of this section.

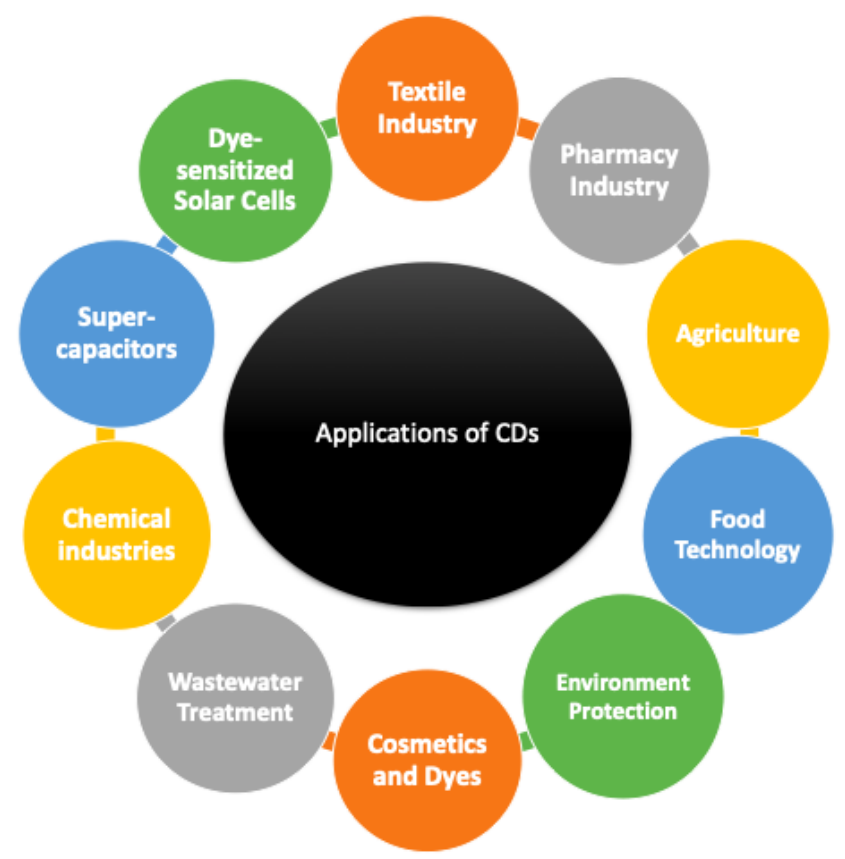

Figure 14. Various Applications of CDs.

\subsection{General Applications}

CDs play an important role in the textile industry, as they can be used as leveling agents in dyeing [223-225], in wastewater treatment [226-228], and in textile finishing [229-233]. In the dyeing process, CDs can be used as a dyeing aid, forming a complex with the dye [234], or as a chemical modification of the surface [235,236]. CDs can form a variety of inclusion complexes with textile dyes, thus influencing the quality of the dyeing.

Some researchers have grafted $\beta-C D$ into insoluble solids, such as activated carbon, zeolite, magnetic materials, and silica gel, obtaining good adsorption results [237]. These adsorbent materials with cyclodextrin incorporation have considerable potential in wastewater treatment applications. This is due to their large amounts of hydroxyl groups, hydrophobic cavity, and interactions with organic and inorganic compounds. 
In the cosmetic sector, CDs are distinguished by odor control, stabilization, and process improvement upon conversion of a liquid ingredient to a solid form [238]. It is used in skin creams, toothpaste, solid and liquid fabric softeners, tissues, paper towels and underarm shields [63].

CDs are also used in food formulations for flavor delivery or flavor protection [64]. Most natural and artificial flavors are volatile oils or liquids and complexation with cyclodextrins provides a favorable substitution to the conventional encapsulation technologies used for flavor protection [63].

They are also used to remove cholesterol from products such as butter, milk, and eggs [4,239]. Materials treated with CDs show 80\% removal of cholesterol $[63,240]$. In Japan, for more than two decades, cyclodextrins have been approved as "modified starch" for food applications, serving to mask odors in fresh food and to stabilize fish oils [63,241]. Also, CDs act as molecular encapsulants, protecting the flavor [182].

CDs are able to reinforce drug delivery through biological membranes. They act as true carriers by keeping the hydrophobic drug molecules in solution and delivering them to the surface of the biological membrane. The addition of $\alpha-C D$ or $\beta-C D$ increases the water solubility of several poorly water-soluble substances. Furthermore, CDs can be used to reduce the effects of irritant or bitter-tasting and bad-smelling drugs [4,239,242,243].

CDs can form complexes with an enormous variety of agricultural chemicals including insecticides, herbicides, repellents, pheromones, fungicides, and growth regulators $[63,182]$. CDs can also be used to delay seed germination. In grain treated with $\beta-C D$, some of the amylases that degrade the starch supplies of the seeds are inhibited, yielding a $20-45 \%$ larger harvest [4].

In the chemical industry, cyclodextrins are often used to separate enantiomers and isomers, to catalyze reactions, to aid in different processes and to detoxify or remove waste materials [63]. They can be used in electrochemical chemistry to mask contaminating compounds [4]. They are also able to serve as enzyme mimics because of the molecular recognition phenomenon [4] attributed to the substituted groups on the CD.

\subsection{CDs in Solar Energy}

Today, energy has become one of the most significant driving forces of economic growth and manufacturing activity. Among the renewable energy resources, solar energy is an essential component of energy usage due to it being safe, easily accessible, and its unlimited nature [244]. Nevertheless, due to the high cost and low performance of some solar energy consumption systems, it is difficult to compete with conventional energy sources. Therefore, an additional priority of researchers, both now and in the near future, is to enable the efficient transfer or storage of solar energy [245]. The heat transfer fluid (HTF) in solar thermal systems plays a crucial role due to its ability to transfer heat from the collector or absorber to the heat exchanger. The brilliant heat transfer efficiency of various nanofluids have been reported [246]. Several studies have shown excellent potential of nanofluids for use mainly in solar energy devices and in the field of heat transfer fluids [247].

On the other hand, semiconductor nanocrystals have attracted enormous attention because of their strong potential for applications in various fields and their excellent physicochemical properties. Feng et al. (2005) presented a self-assembly method based on the special structure of various semiconductor/CD hybrid materials with different morphologies to produce photoactive $\mathrm{TiO}_{2}$-cyclodextrin wires by using CDs as bifunctionals [248] $\beta-C D$ has been found to be valuable in enhancing the kinetics of charge transfer from the photoexcited semiconductor to cavity-absorbed electron acceptors [249]. A low temperature study on $\mathrm{TiO}_{2}-\beta-\mathrm{CD}$-graphene nanocomposite synthesis for energy storage and photocatalytic applications was reported by Sharavath et al. [250]. In a novel route that is a low temperature operation, the $\mathrm{TiO}_{2}-\mathrm{CD} @$ GNS composite was synthesized. After 1000 continuous charge/discharge cycles, it exhibits high capacitance and high cyclic stability with 90 percent capacitance retention. In order to prevent agglomeration, the CD moiety loaded on graphene nanosheets acts as a stabilizing agent for the $\mathrm{TiO}_{2} \mathrm{NPs}$ and has 
served as linkers between them [250]. Obviously, in energy harvesting and storage, the advancement of nanomaterial technology plays a vital role.

In recent years, electrochemical supercapacitors have gained substantial attention because they are capable of providing high power density, rapid charging, a long cycle life, and low maintenance costs. To fabricate high performing electrochemical sensors, CDs are being combined with emerging materials. Coupling the $\mathrm{CDs}$ with graphene nanosheets (GNs) is one of the more exciting combinations; this method is appealing because it results in raising the remarkable electrochemical detection of drugs and biomolecules. The CD-GNs display high supramolecular recognition and enrichment properties of CDs in addition to the good electrical and large surface area properties of GNs [251]. Another motivating blend involves the combination of CDs with carbon nanotubes (CNTs). Combining the attractive properties of the CNTs with the supramolecular inclusion complexation characteristics of the CDs resulted in enhanced electron-transfer reactions at these composites. CD-CNTs displayed an outstanding capability in improving optical properties [252,253]. CDs are combined effectively within a number of conducting polymer matrices (polypyrrole (Ppy), polyaniline (PANI), and polythiophene derivatives) and used as electrochemical sensors. It has been shown that the CDs are the main players in the detection of the objective compounds. They also retain their supramolecular complexation properties [254].

In addition to the above compounds, ordered mesoporous silicas and mesoporous carbon, and 2D layered materials with good conducting properties and high surface areas have been discovered in the development of sensors, including CDs as the molecular recognition agent [255-257]. For a parallel connected supercapacitor and dye-sensitized solar cell, $\beta-C D$ is sulfonated, thermally crosslinked with PVP, and incorporated with $\mathrm{MnCO}_{3}$ nanoparticles. A sulfated composite of $\beta-\mathrm{CD} / \mathrm{PVP} / \mathrm{MnCO}_{3}$ has been thought to provide renewable energy even over long periods in hot environments for a long time [258].

\subsection{Environmental Application of CDs}

In the field of environmental science, CDs play a key role in enhancing and removing organic pollutants and heavy metals from the soil, water and atmosphere, and in the solubility of organic contaminants. Because of their excellent physicochemical properties and their ability to boost the stabilization, encapsulation and adsorption of pollutants, CD-based adsorbents have gained worldwide attention as new-generation adsorbents for wastewater treatment [259]. CD-based adsorbent removal mechanisms partly rely on the preparation process. Singh et al. (2002) stated that after the treatment of wastewater with $\beta-C D$, the levels of all aromatic toxic hydrocarbons such as phenol, $p$-chlorophenol, and benzene present in wastewater are substantially reduced [241].

Furthermore, in environmental fields, CDs have been commonly used as adsorbents and non-toxic cyclic oligosaccharides. The use of CDs in the formulation of insecticides plays a significant role in environmental safety. CDs are integrated into the preparation of a neem seed extract insecticide by creating a water-soluble neem seed kernel extract inclusion complex, enclosing azadirachtin-A in a CD carrier molecule. In addition to all the abovementioned uses, CDs also contribute to the photodegradation process of organophosphorus pesticides in humid water by catalyzing the reaction of reactive radical pesticides formed by the humid photosensitizer and the inclusion of complex CDs [241].

The use of silica beads, with high mechanical properties and physical strength, containing CD molecules with advantages of a complexing substrate as adsorbents has recently received a lot of attention regarding environmental problems $[260,261]$. These combinationsof the silica beads with the $\mathrm{CD}$ result in strong binding affinities toward target pollutants and relatively high pollutant adsorption capacities and are considered as an innovative and promising tool for environmental protection [262].

In short, because of their ability to form complexes with a wide variety of chemicals, CDs have immense application in many industries, and their potential applications in additional areas still deserve further study and consideration. 


\section{Summary and Future Perspectives}

Since their discovery in 1891, CDs have attracted a wide range of research interest in both industry and academia. Among different cyclodextrins forms and their derivatives, we focus in this review on the three native CDs $\alpha-C D, \beta-C D, \gamma-C D$, and some of their derivatives.

The unique chemical structures of $C D$ s is the main reason why they have such a wide variety of applications including drug delivery, wastewater treatment, and pharmaceutical industry. The different sizes of the discussed CDs, along with their wide range of chemical and physical properties such as stabilities, reactivity, and solubility, extend their medical, environmental, and industrial applications.

For example, CDs were used in different fields to address environmental problems such as the formulation of more safe insecticides creating a water-soluble carrier molecule and being utilized for the photodegradation process of organophosphorus pesticides. The CDs biodegradability and biocompatibility give them superior properties for medical applications mainly in drug delivery and the cosmetics industry. CDs are commonly utilized in conventional encapsulation technologies used for food flavor protection, to mask odors in fresh food, and to stabilize fish oils. CDs are also used to remove unwanted molecules such as cholesterol from products like milk, butter, and eggs. CDs are used in the chemical industry to remove waste materials, catalyze reactions, and to separate enantiomers and isomers. In addition to all these usages, CDs are becoming an interesting prospect for solar energy systems due to their promising features of good optical properties, suitable stability, and high thermal conductivity.

We believe that several research areas will continue to conduct further investigation of the synthesis of new cyclodextrin derivatives, and will reveal novel applications of these important molecules. In particular, CDs will be utilized in synthesizing new nanoparticles with designed sizes, as well as fabricating nano-devices for medical applications. For example, Huang et al. (2019) used a $\beta$-CD polymer network (CPN) to synthesize various metal nanoparticles (palladium, silver, platinum, gold, and rhodium) of subnanometer size $(<1 \mathrm{~nm})$ [263].

Author Contributions: B.G.P. conceptualized, drafted, and revised this manuscript. Q.A.A., A.S., E.F.E.A. and F.M. helped with the figures and applications of CDs. A.-H.E., L.J. and M.J. supervised this work, and provided guidance when needed. All authors have read and agreed to the published version of the manuscript.

Funding: This research received no external funding.

Institutional Review Board Statement: Not applicable.

Informed Consent Statement: Not applicable.

Data Availability Statement: Not applicable.

Acknowledgments: We would like to thank King Abdullah University of Science and Technology for financial support.

Conflicts of Interest: There are no conflicts of interest.

\section{References}

1. Szente, L.; Szemán, J.; Sohajda, T. Analytical Characterization of Cyclodextrins: History, Official Methods and Recommended New Techniques. J. Pharm. Biomed. Anal. 2016, 130, 347-365. [CrossRef]

2. Crini, G. Review: A History of Cyclodextrins. Chem. Rev. 2014, 114, 10940-10975. [CrossRef]

3. Crini, G. The Contribution of Franz Schardinger to Cyclodextrins: A Tribute on the Occasion of the Centenary of His Death. J. Incl. Phenom. Macrocycl. Chem. 2020, 97, 19-28. [CrossRef]

4. Szejtli, J. Introduction and General Overview of Cyclodextrin Chemistry. Chem. Rev. 1998, 98, 1743-1754. [CrossRef]

5. French, D. The Schardinger Dextrins. In Advances in Carbohydrate Chemistry; Wolfrom, M.L., Tipson, R.S., Eds.; Academic Press: Cambridge, MA, USA, 1957; Volume 12, pp. 189-260.

6. Martin, J.; Díaz-Montaña, E.J.; Asuero, A.G. Cyclodextrins: Past and Present; IntechOpen: London, UK, 2018; ISBN 978-1-78923-069-7.

7. Freudenberg, K.; Schaaf, E.; Dumpert, G.; Ploetz, T. Neue Ansichten über die Stärke. Naturwissenschaften 1939, 27, 850-853. [CrossRef] 
8. Cramer, F. Einschlussverbindungen; Springer: Berlin/Heidelberg, Germany, 1954.

9. Sharma, N.; Baldi, A. Exploring Versatile Applications of Cyclodextrins: An Overview. Drug Deliv. 2016, 23, 729-747. [CrossRef]

10. Duchêne, D.; Bochot, A. Thirty Years with Cyclodextrins. Int. J. Pharm. 2016, 514, 58-72. [CrossRef]

11. Loftsson, T.; Duchêne, D. Cyclodextrins and Their Pharmaceutical Applications. Int. J. Pharm. 2007, 329, 1-11. [CrossRef]

12. Liu, C.; Zhang, W.; Yang, H.; Sun, W.; Gong, X.; Zhao, J.; Sun, Y.; Diao, G. A Water-Soluble Inclusion Complex of Pedunculoside with the Polymer $\beta$-Cyclodextrin: A Novel Anti-Inflammation Agent with Low Toxicity. PLoS ONE 2014, 9, e101761. [CrossRef]

13. Khalid, S.H.; Bashir, M.; Asghar, S.; Mallhi, T.H.; Khan, I.U. Effect of Cyclodextrin Derivatization on Solubility and Efficacy of Drugs. In Colloid Science in Pharmaceutical Nanotechnology; IntechOpen: London, UK, 2019; ISBN 978-1-78985-596-8.

14. Stella, V.J.; He, Q. Cyclodextrins. Toxicol. Pathol. 2008, 36, 30-42. [CrossRef]

15. Bar, R.; Ulitzur, S. Bacterial Toxicity of Cyclodextrins: Luminuous Escherichia Coli as a Model. Appl. Microbiol. Biotechnol. 1994, 41, 574-577. [CrossRef] [PubMed]

16. Shityakov, S.; Salmas, R.E.; Salvador, E.; Roewer, N.; Broscheit, J.; Förster, C. Evaluation of the Potential Toxicity of Unmodified and Modified Cyclodextrins on Murine Blood-Brain Barrier Endothelial Cells. J. Toxicol. Sci. 2016, 41, 175-184. [CrossRef] [PubMed]

17. Kiss, T.; Fenyvesi, F.; Bácskay, I.; Váradi, J.; Fenyvesi, É.; Iványi, R.; Szente, L.; Tósaki, Á.; Vecsernyés, M. Evaluation of the Cytotoxicity of $\beta$-Cyclodextrin Derivatives: Evidence for the Role of Cholesterol Extraction. Eur. J. Pharm. Sci. 2010, 40, 376-380. [CrossRef] [PubMed]

18. Róka, E.; Ujhelyi, Z.; Deli, M.; Bocsik, A.; Fenyvesi, É.; Szente, L.; Fenyvesi, F.; Vecsernyés, M.; Váradi, J.; Fehér, P.; et al. Evaluation of the Cytotoxicity of $\alpha$-Cyclodextrin Derivatives on the Caco-2 Cell Line and Human Erythrocytes. Molecules 2015, 20, 20269-20285. [CrossRef]

19. Gidwani, B.; Vyas, A. A Comprehensive Review on Cyclodextrin-Based Carriers for Delivery of Chemotherapeutic Cytotoxic Anticancer Drugs. BioMed Res. Int. 2015, 2015, e198268. [CrossRef]

20. Irie, T.; Uekama, K. Pharmaceutical Applications of Cyclodextrins. III. Toxicological Issues and Safety Evaluation. J. Pharm. Sci. 1997, 86, 147-162. [CrossRef]

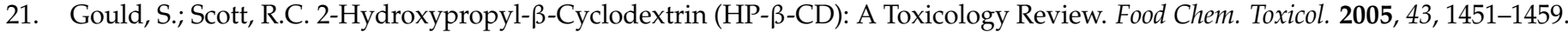
[CrossRef]

22. Braga, S.S. Cyclodextrins: Emerging Medicines of the New Millennium. Biomolecules 2019, 9, 801. [CrossRef]

23. Sikder, M.T.; Rahman, M.M.; Jakariya, M.; Hosokawa, T.; Kurasaki, M.; Saito, T. Remediation of Water Pollution with Native Cyclodextrins and Modified Cyclodextrins: A Comparative Overview and Perspectives. Chem. Eng. J. 2019, 355, 920-941. [CrossRef]

24. Crini, G.; Fourmentin, S.; Fenyvesi, É.; Torri, G.; Fourmentin, M.; Morin-Crini, N. Cyclodextrins, from Molecules to Applications. Environ. Chem. Lett. 2018, 16, 1361-1375. [CrossRef]

25. Rincón-López, J.; Almanza-Arjona, Y.C.; Riascos, A.P.; Rojas-Aguirre, Y. Technological Evolution of Cyclodextrins in the Pharmaceutical Field. J. Drug Deliv. Sci. Technol. 2021, 61, 102156. [CrossRef] [PubMed]

26. Loftsson, T. Cyclodextrins in Parenteral Formulations. J. Pharm. Sci. 2021, 110, 654-664. [CrossRef] [PubMed]

27. Mura, P. Advantages of the Combined Use of Cyclodextrins and Nanocarriers in Drug Delivery: A Review. Int. J. Pharm. 2020, 579, 119181. [CrossRef] [PubMed]

28. Jones, S.T.; Cagno, V.; Janeček, M.; Ortiz, D.; Gasilova, N.; Piret, J.; Gasbarri, M.; Constant, D.A.; Han, Y.; Vuković, L.; et al. Modified Cyclodextrins as Broad-Spectrum Antivirals. Sci. Adv. 2020, 6, eaax9318. [CrossRef] [PubMed]

29. Song, L.X.; Bai, L.; Xu, X.M.; He, J.; Pan, S.Z. Inclusion Complexation, Encapsulation Interaction and Inclusion Number in Cyclodextrin Chemistry. Coord. Chem. Rev. 2009, 253, 1276-1284. [CrossRef]

30. Dos Santos, C.; Buera, P.; Mazzobre, F. Novel Trends in Cyclodextrins Encapsulation. Applications in Food Science. Curr. Opin. Food Sci. 2017, 16, 106-113. [CrossRef]

31. Hamoudi, M.C.; Bochot, A. Oil-Cyclodextrin Based Beads for Oral Delivery of Poorly-Soluble Drugs. Curr. Top. Med. Chem. 2014, 14, 510-517. [CrossRef] [PubMed]

32. Calleja, P.; Huarte, J.; Agüeros, M.; Ruiz-Gatón, L.; Espuelas, S.; Irache, J.M. Molecular Buckets: Cyclodextrins for Oral Cancer Therapy. Ther. Deliv. 2012, 3, 43-57. [CrossRef]

33. Carrier, R.L.; Miller, L.A.; Ahmed, I. The Utility of Cyclodextrins for Enhancing Oral Bioavailability. J. Control. Release Off. J. Control. Release Soc. 2007, 123, 78-99. [CrossRef]

34. Maheriya, P.M. Cyclodextrin: A Promising Candidate in Enhancing Oral Bioavailability of Poorly Water Soluble Drugs. MOJ Bioequiv. Bioavailab. 2017, 3, 60-63. [CrossRef]

35. Singh, N.; Sahu, O. 4-Sustainable Cyclodextrin in Textile Applications. In The Impact and Prospects of Green Chemistry for Textile Technology; Ul-Islam, S., Butola, B.S., Eds.; The Textile Institute Book Series; Woodhead Publishing: Sawston, UK, 2019; pp. 83-105, ISBN 978-0-08-102491-1.

36. Li, Z.; Chen, S.; Gu, Z.; Chen, J.; Wu, J. Alpha-Cyclodextrin: Enzymatic Production and Food Applications. Trends Food Sci. Technol. 2014, 35, 151-160. [CrossRef]

37. Szente, L.; Szejtli, J. Cyclodextrins as Food Ingredients. Trends Food Sci. Technol. 2004, 15, 137-142. [CrossRef]

38. Buschmann, H.-J.; Schollmeyer, E. Applications of Cyclodextrins in Cosmetic Products: A Review. J. Cosmet. Sci. 2002, 53, 185-191. [PubMed] 
39. Jullien, L.; Canceill, J.; Valeur, B.; Bardez, E.; Lefèvre, J.-P.; Lehn, J.-M.; Marchi-Artzner, V.; Pansu, R. Multichromophoric Cyclodextrins. 4. Light Conversion by Antenna Effect. J. Am. Chem. Soc. 1996, 118, 5432-5442. [CrossRef]

40. Hajdu, C.; Gruiz, K.; Fenyvesi, É.; Nagy, Z.M. Application of Cyclodextrins in Environmental Bioassays for Soil. J. Incl. Phenom. Macrocycl. Chem. 2011, 70, 307-313. [CrossRef]

41. Morillo, E.; Madrid, F.; Lara-Moreno, A.; Villaverde, J. Soil Bioremediation by Cyclodextrins: A Review. Int. J. Pharm. 2020, 591, 119943. [CrossRef] [PubMed]

42. Saokham, P.; Muankaew, C.; Jansook, P.; Loftsson, T. Solubility of Cyclodextrins and Drug/Cyclodextrin Complexes. Molecules 2018, 23, 1161. [CrossRef]

43. Gaidamauskas, E.; Norkus, E.; Butkus, E.; Crans, D.C.; Grincienė, G. Deprotonation of $\beta$-Cyclodextrin in Alkaline Solutions. Carbohydr. Res. 2009, 344, 250-254. [CrossRef] [PubMed]

44. Szejtli, J. Past, present and futute of cyclodextrin research. Pure Appl. Chem. 2004, 76, 1825-1845. [CrossRef]

45. Bender, M.L.; Komiyama, M. Cyclodextrin Chemistry; Reactivity and Structure: Concepts in Organic Chemistry; Springer: Berlin/Heidelberg, Germany, 1978; ISBN 978-3-642-66844-9.

46. Tegge, G.; Szejtli, J. Cyclodextrins and Their Inclusion Complexes (Cyclodextrine und Ihre Einschlußkomplexe). Verlag Der Ungarischen Akademie Der Wissenschaften. Akadémiai Kiadó, Budapest 1982. 296 Pages, with Numerous Tables and Formulas, Cloth DM 67,50. Starch-Stärke 1982, 34, 395. [CrossRef]

47. Dodziuk, H. Molecules with Holes-Cyclodextrins. In Cyclodextrins and Their Complexes; John Wiley \& Sons, Ltd.: Hoboken, NJ, USA, 2006; pp. 1-30, ISBN 978-3-527-60898-0.

48. Alvarez-Dorta, D.; León, E.I.; Kennedy, A.R.; Martín, A.; Pérez-Martín, I.; Suárez, E. Easy Access to Modified Cyclodextrins by an Intramolecular Radical Approach. Angew. Chem. Int. Ed. 2015, 54, 3674-3678. [CrossRef] [PubMed]

49. Harata, K. Crystallographic Study of Cyclodextrins and Their Inclusion Complexes. In Cyclodextrins and Their Complexes; John Wiley \& Sons, Ltd.: Hoboken, NJ, USA, 2006; pp. 147-198, ISBN 978-3-527-60898-0.

50. Plazinski, W.; Drach, M. The Dynamics of the Conformational Changes in the Hexopyranose Ring: A Transition Path Sampling Approach. RSC Adv. 2014, 4, 25028-25039. [CrossRef]

51. Saenger, W.; Jacob, J.; Gessler, K.; Steiner, T.; Hoffmann, D.; Sanbe, H.; Koizumi, K.; Smith, S.M.; Takaha, T. Structures of the Common Cyclodextrins and Their Larger AnaloguesBeyond the Doughnut. Chem. Rev. 1998, 98, 1787-1802. [CrossRef] [PubMed]

52. Caira, M.R.; Griffith, V.J.; Nassimbeni, L.R.; van Oudtshoorn, B. Unusual 1C4 Conformation of a Methylglucose Residue in Crystalline Permethyl- $\beta$-Cyclodextrin Monohydrate. J. Chem. Soc. Perkin Trans. 2 1994, 10, 2071-2072. [CrossRef]

53. Voncina, B.; Vivod, V. Cyclodextrins in Textile Finishing; IntechOpen: London, UK, 2013; ISBN 978-953-51-0892-4.

54. Van de Manakker, F.; Vermonden, T.; van Nostrum, C.F.; Hennink, W.E. Cyclodextrin-Based Polymeric Materials: Synthesis, Properties, and Pharmaceutical/Biomedical Applications. Biomacromolecules 2009, 10, 3157-3175. [CrossRef]

55. Parmar, V.; Patel, G.; Abu-Thabit, N.Y. 20-Responsive Cyclodextrins as Polymeric Carriers for Drug Delivery Applications. In Stimuli Responsive Polymeric Nanocarriers for Drug Delivery Applications; Makhlouf, A.S.H., Abu-Thabit, N.Y., Eds.; Woodhead Publishing Series in Biomaterials; Woodhead Publishing: Sawston, UK, 2018; Volume 1, pp. 555-580, ISBN 978-0-08-101997-9.

56. Loftsson, T.; Jarho, P.; Másson, M.; Järvinen, T. Cyclodextrins in Drug Delivery. Expert Opin. Drug Deliv. $2005,2,335-351$. [CrossRef]

57. Connors, K.A. The Stability of Cyclodextrin Complexes in Solution. Chem. Rev. 1997, 97, 1325-1358. [CrossRef]

58. Noreña-Caro, D.; Alvarez-Láinez, M. Experimental Design as a Tool for the Manufacturing of Filtering Media Based on Electrospun Polyacrylonitrile/ $\beta$-Cyclodextrin Fibers. Int. J. Interact. Des. Manuf. IJIDeM 2016, 10, 153-164. [CrossRef]

59. Cova, T.F.; Murtinho, D.; Pais, A.A.C.C.; Valente, A.J.M. Combining Cellulose and Cyclodextrins: Fascinating Designs for Materials and Pharmaceutics. Front. Chem. 2018, 6, 271. [CrossRef]

60. Michoff, M.E.Z.; Granados, A.M.; de Rossi, R.H. Study of the Interaction of 5-(Alkylthio)-3H-1, 2-Dithiole-3-Thiones with $\beta$-Cyclodextrin; Michigan Publishing-University of Michigan Library: Ann Arbor, MI, USA, 2005.

61. Challa, R.; Ahuja, A.; Ali, J.; Khar, R.K. Cyclodextrins in Drug Delivery: An Updated Review. AAPS PharmSciTech 2005, 6, E329-E357. [CrossRef]

62. Atwood, J.L. Inclusion (Clathrate) Compounds. In Encyclopedia of Physical Science and Technology, 3rd ed.; Meyers, R.A., Ed.; Academic Press: New York, NY, USA, 2003; pp. 717-729, ISBN 978-0-12-227410-7.

63. Del Valle, E.M.M. Cyclodextrins and Their Uses: A Review. Process Biochem. 2004, 39, 1033-1046. [CrossRef]

64. Loftsson, T.; Brewster, M.E. Pharmaceutical Applications of Cyclodextrins: Basic Science and Product Development. J. Pharm. Pharmacol. 2010, 62, 1607-1621. [CrossRef]

65. Cal, K.; Centkowska, K. Use of Cyclodextrins in Topical Formulations: Practical Aspects. Eur. J. Pharm. Biopharm. 2008, 68, 467-478. [CrossRef] [PubMed]

66. Hybl, A.; Rundle, R.E.; Williams, D.E. The Crystal and Molecular Structure of the Cyclohexaamylose-Potassium Acetate Complex1. J. Am. Chem. Soc. 1965, 87, 2779-2788. [CrossRef]

67. Hamilton, J.A.; Sabesan, M.N.; Steinrauf, L.K. Structure of Cycloheptaamylose Inclusion-Complexes: Crystal Structure of Substituted Benzoic Acid and Phenol Derivatives. Carbohydr. Res. 1981, 89, 33-53. [CrossRef]

68. Maclennan, J.M.; Stezowski, J.J. The Crystal Structure of Uncomplexed-Hydrated Cyclooctaamylose. Biochem. Biophys. Res. Commun. 1980, 92, 926-932. [CrossRef] 
69. Zhang, J.; Ma, P.X. Cyclodextrin-Based Supramolecular Systems for Drug Delivery: Recent Progress and Future Perspective. Adv. Drug Deliv. Rev. 2013, 65, 1215-1233. [CrossRef]

70. Davis, M.E.; Brewster, M.E. Cyclodextrin-Based Pharmaceutics: Past, Present and Future. Nat. Rev. Drug Discov. 2004, 3, 1023-1035. [CrossRef]

71. Loftsson, T.; Brewster, M.E. Cyclodextrins as Functional Excipients: Methods to Enhance Complexation Efficiency. J. Pharm. Sci. 2012, 101, 3019-3032. [CrossRef] [PubMed]

72. Muankaew, C.; Loftsson, T. Cyclodextrin-Based Formulations: A Non-Invasive Platform for Targeted Drug Delivery. Basic Clin Pharmacol. Toxicol. 2018, 122, 46-55. [CrossRef]

73. Chu, H.M.; Zhang, R.X.; Huang, Q.; Bai, C.C.; Wang, Z.Z. Chemical Conjugation with Cyclodextrins as a Versatile Tool for Drug Delivery. J. Incl. Phenom. Macrocycl. Chem. 2017, 89, 29-38. [CrossRef]

74. Schmidt, B.V.K.J.; Barner-Kowollik, C. Dynamic Macromolecular Material Design-The Versatility of Cyclodextrin-Based HostGuest Chemistry. Angew. Chem. Int. Ed. 2017, 56, 8350-8369. [CrossRef] [PubMed]

75. Heidel, J.D.; Schluep, T. Cyclodextrin-Containing Polymers: Versatile Platforms of Drug Delivery Materials. J. Drug Deliv. 2012, 2012, e262731. [CrossRef] [PubMed]

76. Arora, P.; Dhingra, N. Cyclodextrin-A Versatile Ingredient; BoD—Books on Demand: Norderstedt, Germany, 2018; ISBN 978-178923-069-7.

77. Bell, A.F.; Hecht, L.; Barron, L.D. New Evidence for Conformational Flexibility in Cyclodextrins from Vibrational Raman Optical Activity. Chem.-Eur. J. 1997, 3, 1292-1298. [CrossRef]

78. Schneider, H.-J.; Hacket, F.; Rüdiger, V.; Ikeda, H. NMR Studies of Cyclodextrins and Cyclodextrin Complexes. Chem. Rev. 1998, 98, 1755-1786. [CrossRef]

79. Yamamoto, Y.; Inoue, Y. NMR Studies of Cyclodextrin Inclusion Complex. J. Carbohydr. Chem. 1989, 8, 29-46. [CrossRef]

80. Dodziuk, H.; Koźmiński, W.; Ejchart, A. NMR Studies of Chiral Recognition by Cyclodextrins. Chirality 2004, 16, 90-105. [CrossRef]

81. Dodziuk, H.; Ejchart, A.; Lukin, O.; Vysotsky, M.O. 1H and 13C NMR and Molecular Dynamics Study of Chiral Recognition of Camphor Enantiomers by $\alpha$-Cyclodextrin. J. Org. Chem. 1999, 64, 1503-1507. [CrossRef]

82. Ejchart, A.; Koźmiński, W. NMR of Cyclodextrins and Their Complexes. In Cyclodextrins and Their Complexes; John Wiley \& Sons, Ltd.: Hoboken, NJ, USA, 2006; pp. 231-254, ISBN 978-3-527-60898-0.

83. Dodziuk, H. Rigidity versus Flexibility. A Review of Experimental and Theoretical Studies Pertaining to the Cyclodextrin Nonrigidity. J. Mol. Struct. 2002, 614, 33-45. [CrossRef]

84. Fujita, K.; Chen, W.-H.; Yuan, D.-Q.; Nogami, Y.; Koga, T.; Fujioka, T.; Mihashi, K.; Immel, S.; Lichtenthaler, F.W. Guest-Induced Conformational Change in a Flexible Host: Mono-Altro- $\beta$-Cyclodextrin1Part 20 of the Series Molecular Modeling of Saccharides. Tetrahedron Asymmetry 1999, 10, 1689-1696. [CrossRef]

85. Kozár, T.; Venanzi, C.A. Reconsidering the Conformational Flexibility of $\beta$-Cyclodextrin. J. Mol. Struct. THEOCHEM 1997, 395-396, 451-468. [CrossRef]

86. Ishizu, T.; Hirata, C.; Yamamoto, H.; Harano, K. Structure and Intramolecular Flexibility of Beta-Cyclodextrin Complex with (-)-Epigallocatechin Gallate in Aqueous Solvent. Magn. Reson. Chem. MRC 2006, 44, 776-783. [CrossRef] [PubMed]

87. Raffaini, G.; Ganazzoli, F. Hydration and Flexibility of $\alpha-, \beta-, \gamma$ - and $\delta$-Cyclodextrin: A Molecular Dynamics Study. Chem. Phys. 2007, 333, 128-134. [CrossRef]

88. Cova, T.F.; Milne, B.F.; Pais, A.A.C.C. Host Flexibility and Space Filling in Supramolecular Complexation of Cyclodextrins: A Free-Energy-Oriented Approach. Carbohydr. Polym. 2019, 205, 42-54. [CrossRef] [PubMed]

89. Sandilya, A.A.; Natarajan, U.; Priya, M.H. Molecular View into the Cyclodextrin Cavity: Structure and Hydration. ACS Omega 2020, 5, 25655-25667. [CrossRef] [PubMed]

90. Pinjari, R.V.; Joshi, K.A.; Gejji, S.P. Molecular Electrostatic Potentials and Hydrogen Bonding in $\alpha-, \beta-$, and $\gamma$-Cyclodextrins. J. Phys. Chem. A 2006, 110, 13073-13080. [CrossRef]

91. Sonnendecker, C.; Thürmann, S.; Przybylski, C.; Zitzmann, F.D.; Heinke, N.; Krauke, Y.; Monks, K.; Robitzki, A.A.; Belder, D.; Zimmermann, W. Large-Ring Cyclodextrins as Chiral Selectors for Enantiomeric Pharmaceuticals. Angew. Chem. Int. Ed. 2019, 58, 6411-6414. [CrossRef]

92. Ueda, H.; Endo, T. Large-Ring Cyclodextrins. In Cyclodextrins and Their Complexes; John Wiley \& Sons, Ltd.: Hoboken, NJ, USA, 2006; pp. 370-380, ISBN 978-3-527-60898-0.

93. Larsen, K.L. Large Cyclodextrins. J. Incl. Phenom. Macrocycl. Chem. 2002, 43, 1-13. [CrossRef]

94. Ueda, H. Physicochemical Properties and Complex Formation Abilities of Large-Ring Cyclodextrins. J. Incl. Phenom. Macrocycl. Chem. 2002, 44, 53-56. [CrossRef]

95. Szejtli, J. Cyclodextrin Inclusion Complexes. In Cyclodextrin Technology; Szejtli, J., Ed.; Topics in Inclusion Science; Springer: Dordrecht, The Netherlands, 1988; pp. 79-185, ISBN 978-94-015-7797-7.

96. Saenger, W. Cyclodextrin Inclusion Compounds in Research and Industry. Angew. Chem. Int. Ed. 1980, 19, 344-362. [CrossRef]

97. Naidoo, K.J.; Gamieldien, M.R.; Chen, J.Y.-J.; Widmalm, G.; Maliniak, A. Glucose Orientation and Dynamics in $\alpha-$, $\beta-$, and $\gamma$-Cyclodextrins. J. Phys. Chem. B 2008, 112, 15151-15157. [CrossRef] [PubMed] 
98. Saenger, W. Structure Aspects of Cyclodextrin Inclusion Compounds. In Proceedings of the First International Symposium on Cyclodextrins, Budapest, Hungary, 30 September-2 October 1981; Szejtli, J., Ed.; Springer: Dordrecht, The Netherlands, 1982; pp. 141-150.

99. Franzini, R.; Ciogli, A.; Gasparrini, F.; Ismail, O.H.; Villani, C. Chapter 14-Recent Developments in Chiral Separations by Supercritical Fluid Chromatography. In Chiral Analysis, 2nd ed.; Polavarapu, P.L., Ed.; Elsevier: Amsterdam, The Netherlands, 2018; pp. 607-629, ISBN 978-0-444-64027-7.

100. Tafazzoli, M.; Ghiasi, M. Structure and Conformation of $\alpha-, \beta$ - and $\gamma$-Cyclodextrin in Solution: Theoretical Approaches and Experimental Validation. Carbohydr. Polym. 2009, 78, 10-15. [CrossRef]

101. Jarvis, M.C. Relationship of Chemical Shift to Glycosidic Conformation in the Solid-State13C NMR Spectra of $(1 \rightarrow 4)$-Linked Glucose Polymers and Oligomers: Anomeric and Related Effects. Carbohydr. Res. 1994, 259, 311-318. [CrossRef]

102. Miller, M.M.; Wasik, S.P.; Huang, G.L.; Shiu, W.Y.; Mackay, D. Relationships between Octanol-Water Partition Coefficient and Aqueous Solubility. Environ. Sci. Technol. 1985, 19, 522-529. [CrossRef] [PubMed]

103. Hedges, A. Chapter 22-Cyclodextrins: Properties and Applications. In Starch, 3rd ed.; BeMiller, J., Whistler, R., Eds.; Food Science and Technology; Academic Press: San Diego, CA, USA, 2009; pp. 833-851, ISBN 978-0-12-746275-2.

104. Saha, S.; Roy, A.; Roy, K.; Roy, M.N. Study to Explore the Mechanism to Form Inclusion Complexes of $\beta$-Cyclodextrin with Vitamin Molecules. Sci. Rep. 2016, 6, 35764. [CrossRef]

105. Sabadini, E.; Cosgrove, T.; do Carmo Egídio, F. Solubility of Cyclomaltooligosaccharides (Cyclodextrins) in H2O and D2O: A Comparative Study. Carbohydr. Res. 2006, 341, 270-274. [CrossRef]

106. Jiang, L.; Yan, Y.; Huang, J. Versatility of Cyclodextrins in Self-Assembly Systems of Amphiphiles. Adv. Colloid Interface Sci. 2011, 169, 13-25. [CrossRef]

107. Schneiderman, E.; Stalcup, A.M. Cyclodextrins: A Versatile Tool in Separation Science. J. Chromatogr. B Biomed. Sci. Appl. 2000, 745, 83-102. [CrossRef]

108. Alvarez-Lorenzo, C.; García-González, C.A.; Concheiro, A. Cyclodextrins as Versatile Building Blocks for Regenerative Medicine. J. Control. Release 2017, 268, 269-281. [CrossRef]

109. Küster, T.; Stadelmann, B.; Aeschbacher, D.; Hemphill, A. Activities of Fenbendazole in Comparison with Albendazole against Echinococcus Multilocularis Metacestodes in Vitro and in a Murine Infection Model. Int. J. Antimicrob. Agents 2014, 43, 335-342. [CrossRef]

110. Rodrigues, L.N.C.; Tavares, A.C.M.; Ferreira, B.T.; Reis, A.K.C.A.; Katiki, L.M. Inclusion Complexes and Self-Assembled Cyclodextrin Aggregates for Increasing the Solubility of Benzimidazoles. Braz. J. Pharm. Sci. 2019, 55. [CrossRef]

111. Ren, J.; Zhang, R.; Regenstein, J.M. 13-Adding Biological Function to Nonbiological Nanoparticles. In Nutrient Delivery; Nanotechnology in the Agri-Food Industry; Grumezescu, A.M., Ed.; Academic Press: Cambridge, MA, USA, 2017; pp. 497-534, ISBN 978-0-12-804304-2

112. Laza-Knoerr, A.L.; Gref, R.; Couvreur, P. Cyclodextrins for Drug Delivery. J. Drug Target. 2010, 18, 645-656. [CrossRef] [PubMed]

113. Otero-Espinar, F.J.; Torres-Labandeira, J.J.; Alvarez-Lorenzo, C.; Blanco-Méndez, J. Cyclodextrins in Drug Delivery Systems. J. Drug Deliv. Sci. Technol. 2010, 20, 289-301. [CrossRef]

114. Haimhoffer, Á.; Rusznyák, Á.; Réti-Nagy, K.; Vasvári, G.; Váradi, J.; Vecsernyés, M.; Bácskay, I.; Fehér, P.; Ujhelyi, Z.; Fenyvesi, F. Cyclodextrins in Drug Delivery Systems and Their Effects on Biological Barriers. Sci. Pharm. 2019, 87, 33. [CrossRef]

115. Eastburn, S.D.; Tao, B.Y. Applications of Modified Cyclodextrins. Biotechnol. Adv. 1994, 12, 325-339. [CrossRef]

116. Seltzman, H.H.; Szulc, Z.M. Chemically Modified Cyclodextrins as Catalytic Enzyme Mimics. In Proceedings of the Eighth International Symposium on Cyclodextrins, Budapest, Hungary, 31 March-2 April 1996; Szejtli, J., Szente, L., Eds.; Springer: Dordrecht, The Netherlands, 1996; pp. 267-272.

117. Kataky, R.; Morgan, E. Potential of Enzyme Mimics in Biomimetic Sensors: A Modified-Cyclodextrin as a Dehydrogenase Enzyme Mimic. Biosens. Bioelectron. 2003, 18, 1407-1417. [CrossRef]

118. Dagani, R. Supramolecular chemistry-polymeric nanotubes made from sugars. Chem. Eng. News 1993, $71,4$.

119. Yaksh, T.L.; Jang, J.; Nishiuchi, Y.; Braun, K.P.; Ro, S.; Goodman, M. The Utility of 2-Hydroxypropyl- $\beta$-Cyclodextrin as a Vehicle for the Intracerebral and Intrathecal Administration of Drugs. Life Sci. 1991, 48, 623-633. [CrossRef]

120. Adachi, H.; Irie, T.; Harayama, F.; Uekame, K. Stabilization of Prostaglandin $E_{1}$ in Fatty Alcohol Propylene Glycol Ointment by Acidic Cyclodextrin Derivative, O-Carboxymethyl-O-Ethyl- $\beta$-Cyclodextrin. Chem. Pharm. Bull. 1992, 40, 1586-1591. [CrossRef]

121. Ueno, A.; Kuwabara, T.; Nakamura, A.; Toda, F.; Kuwabara, T.; Nakamura, A.; Toda, F. A Modified Cyclodextrin as a Guest Responsive Colour-Change Indicator. Nature 1992, 356, 136-137. [CrossRef]

122. Schmarr, H.-G.; Mosandl, A.; Neukom, H.-P.; Grob, K. Modified Cyclodextrins as Stationary Phases for Capillary GC: Consequences of Dilution in Polysiloxanes. J. High Resolut. Chromatogr. 1991, 14, 207-210. [CrossRef]

123. Otake, T.; Schols, D.; Witvrouw, M.; Naesens, L.; Nakashima, H.; Moriya, T.; Kurita, H.; Matsumoto, K.; Ueba, N.; De Clercq, E. Modified Cyclodextrin Sulphates(MCDS11) Have Potent Inhibitory Activity against HIV and High Oral Bioavailability. Antivir. Chem. Chemother. 1994, 5, 155-161. [CrossRef]

124. Astray, G.; Gonzalez-Barreiro, C.; Mejuto, J.C.; Rial-Otero, R.; Simal-Gándara, J. A Review on the Use of Cyclodextrins in Foods. Food Hydrocoll. 2009, 23, 1631-1640. [CrossRef]

125. Kaatze, U. Acoustical Spectroscopy of Carbohydrate Aqueous Solutions: Saccharides; Alkyl Glycosides; Cyclodextrins. Part I. Conformer Variations. Arch. Acoust. 2010, 35, 715-738. [CrossRef] 
126. Rather, M.Y.; Nordberg Karlsson, E.; Adlercreutz, P. Complexation of Alkyl Glycosides with $\alpha$-Cyclodextrin Can Have Drastically Different Effects on Their Conversion by Glycoside Hydrolases. J. Biotechnol. 2015, 200, 52-58. [CrossRef] [PubMed]

127. Rather, M.Y.; Ara, K.Z.G.; Nordberg Karlsson, E.; Adlercreutz, P. Characterization of Cyclodextrin Glycosyltransferases (CGTases) and Their Application for Synthesis of Alkyl Glycosides with Oligomeric Head Group. Process Biochem. 2015, 50, 722-728. [CrossRef]

128. Schurig, V. Use of Derivatized Cyclodextrins as Chiral Selectors for the Separation of Enantiomers by Gas Chromatography. Ann. Pharm. Fr. 2010, 68, 82-98. [CrossRef]

129. Liu, Y.; Li, L.; Zhang, H.-Y.; Fan, Z.; Guan, X.-D. Selective Binding of Chiral Molecules of Cinchona Alkaloid by Beta- and Gamma-Cyclodextrins and Organoselenium-Bridged Bis(Beta-Cyclodextrin)s. Bioorgan. Chem. 2003, 31, 11-23. [CrossRef]

130. Cai, W.; Yu, Y.; Shao, X. Chiral Recognition of Aromatic Compounds by $\beta$-Cyclodextrin Based on Bimodal Complexation. J. Mol. Model. 2005, 11, 186-193. [CrossRef]

131. Rekharsky, M.V.; Inoue, Y. Complexation and Chiral Recognition Thermodynamics of 6-Amino-6-Deoxy- $\beta$-Cyclodextrin with Anionic, Cationic, and Neutral Chiral Guests: Counterbalance between van Der Waals and Coulombic Interactions. J. Am. Chem. Soc. 2002, 124, 813-826. [CrossRef]

132. Rogez-Florent, T.; Azaroual, N.; Goossens, L.; Goossens, J.-F.; Danel, C. NMR Investigation of the Complexation and Chiral Discrimination of Pyrazole Sulfonamide Derivatives with Cyclodextrins. Carbohydr. Polym. 2015, 115, 598-604. [CrossRef]

133. Zerbinati, O.; Trotta, F.; Giovannoli, C.; Baggiani, C.; Giraudi, G.; Vanni, A. New Derivatives of Cyclodextrins as Chiral Selectors for the Capillary Electrophoretic Separation of Dichlorprop Enantiomers. J. Chromatogr. A 1998, 810, 193-200. [CrossRef]

134. Harada, A.; Adachi, H.; Kawaguchi, Y.; Kamachi, M. Recognition of Alkyl Groups on a Polymer Chain by Cyclodextrins. Macromolecules 1997, 30, 5181-5182. [CrossRef]

135. Monteil, M.; Lecouvey, M.; Landy, D.; Ruellan, S.; Mallard, I. Cyclodextrins: A Promising Drug Delivery Vehicle for Bisphosphonate. Carbohydr. Polym. 2017, 156, 285-293. [CrossRef] [PubMed]

136. DiScenza, D.J.; Levine, M. Selective Detection of Non-Aromatic Pesticides via Cyclodextrin-Promoted Fluorescence Modulation. New J. Chem. 2016, 40, 789-793. [CrossRef]

137. Šoškić, M.; Porobić, I. Interactions of Indole Derivatives with $\beta$-Cyclodextrin: A Quantitative Structure-Property Relationship Study. PLoS ONE 2016, 11, e0154339. [CrossRef] [PubMed]

138. Wang, M.S.; Boddapati, S.; Sierks, M.R. Cyclodextrins Promote Protein Aggregation Posing Risks for Therapeutic Applications. Biochem. Biophys. Res. Commun. 2009, 386, 526-531. [CrossRef]

139. Łagiewka, J.; Girek, T.; Ciesielski, W. Cyclodextrins-Peptides/Proteins Conjugates: Synthesis, Properties and Applications. Polymers 2021, 13, 1759. [CrossRef]

140. Oliveri, V.; Vecchio, G. Cyclodextrins as Protective Agents of Protein Aggregation: An Overview. Chem. Asian J. 2016, 11, 1648-1657. [CrossRef]

141. Serno, T.; Geidobler, R.; Winter, G. Protein Stabilization by Cyclodextrins in the Liquid and Dried State. Adv. Drug Deliv. Rev. 2011, 63, 1086-1106. [CrossRef]

142. Carrazana, J.; Jover, A.; Meijide, F.; Soto, V.H.; Vázquez Tato, J. Complexation of Adamantyl Compounds by $\beta$-Cyclodextrin and Monoaminoderivatives. J. Phys. Chem. B 2005, 109, 9719-9726. [CrossRef] [PubMed]

143. Ngan Tran, D.; Colesnic, D.; de Beaumais, S.A.; Pembouong, G.; Portier, F.; Antelo Queijo, Á.; Tato, J.V.; Zhang, Y.; Ménand, M.; Bouteiller, L.; et al. Cyclodextrin-Adamantane Conjugates, Self-Inclusion and Aggregation versus Supramolecular Polymer Formation. Org. Chem. Front. 2014, 1, 703-706. [CrossRef]

144. Díaz, D.; Escobar Llanos, C.M.; Bernad, M.J.; Mora, J.G. Binding, Molecular Mechanics, and Thermodynamics of Cyclodextrin Inclusion Complexes with Ketoprofen in Aqueous Medium. Pharm. Dev. Technol. 1998, 3, 307-313. [CrossRef] [PubMed]

145. Assaf, K.I.; Ural, M.S.; Pan, F.; Georgiev, T.; Simova, S.; Rissanen, K.; Gabel, D.; Nau, W.M. Water Structure Recovery in Chaotropic Anion Recognition: High-Affinity Binding of Dodecaborate Clusters to $\gamma$-Cyclodextrin. Angew. Chem. Int. Ed. 2015, 54, 6852-6856. [CrossRef]

146. Voskuhl, J.; Waller, M.; Bandaru, S.; Tkachenko, B.A.; Fregonese, C.; Wibbeling, B.; Schreiner, P.R.; Ravoo, B.J. Nanodiamonds in Sugar Rings: An Experimental and Theoretical Investigation of Cyclodextrin-Nanodiamond Inclusion Complexes. Org. Biomol. Chem. 2012, 10, 4524-4530. [CrossRef] [PubMed]

147. Jambhekar, S.S.; Breen, P. Cyclodextrins in Pharmaceutical Formulations I: Structure and Physicochemical Properties, Formation of Complexes, and Types of Complex. Drug Discov. Today 2016, 21, 356-362. [CrossRef] [PubMed]

148. Charumanee, S.; Titwan, A.; Sirithunyalug, J.; Weiss-Greiler, P.; Wolschann, P.; Viernstein, H.; Okonogi, S. Thermodynamics of the Encapsulation by Cyclodextrins. J. Chem. Technol. Biotechnol. 2006, 81, 523-529. [CrossRef]

149. Rekharsky, M.V.; Inoue, Y. Complexation Thermodynamics of Cyclodextrins. Chem. Rev. 1998, 98, 1875-1918. [CrossRef]

150. Brett, J. Goldilocks and the Three Bears; Penguin: London, UK, 2016.

151. Szente, L.; Singhal, A.; Domokos, A.; Song, B. Cyclodextrins: Assessing the Impact of Cavity Size, Occupancy, and Substitutions on Cytotoxicity and Cholesterol Homeostasis. Molecules 2018, 23, 1228. [CrossRef]

152. Saad, H.Y.; Higuchi, W.I. Water Solubility of Cholesterol. J. Pharm. Sci. 1965, 54, 1205-1206. [CrossRef]

153. Ohtani, Y.; Irie, T.; Uekama, K.; Fukunaga, K.; Pitha, J. Differential Effects of $\alpha-, \beta$ - and $\gamma$-Cyclodextrins on Human Erythrocytes. Eur. J. Biochem. 1989, 186, 17-22. [CrossRef] [PubMed] 
154. Irie, T.; Otagiri, M.; Sunada, M.; Uekama, K.; Ohtani, Y.; Yamada, Y.; Sugiyama, Y. Cyclodextrin-Induced Hemolysis and Shape Changes of Human Erythrocytes in Vitro. J. Pharmacobiodyn. 1982, 5, 741-744. [CrossRef] [PubMed]

155. Yang, B.; Yang, L.-J.; Lin, J.; Chen, Y.; Liu, Y. Binding Behaviors of Scutellarin with $\alpha-, \beta-, \gamma-C y c l o d e x t r i n s$ and Their Derivatives. J. Incl. Phenom. Macrocycl. Chem. 2009, 64, 149. [CrossRef]

156. Wójcik, J.; Ejchart, A.; Nowakowski, M. Shape Adaptation of Quinine in Cyclodextrin Cavities: NMR Studies. Phys. Chem. Chem. Phys. 2019, 21, 6925-6934. [CrossRef] [PubMed]

157. Cova, T.F.G.G.; Cruz, S.M.A.; Valente, A.J.M.; Abreu, P.E.; Marques, J.M.C.; Pais, A.A.C.C. Aggregation of Cyclodextrins: Fundamental Issues and Applications; IntechOpen: London, UK, 2018; ISBN 978-1-78923-069-7.

158. Ryzhakov, A.; Do Thi, T.; Stappaerts, J.; Bertoletti, L.; Kimpe, K.; Sá Couto, A.R.; Saokham, P.; Van den Mooter, G.; Augustijns, P.; Somsen, G.W.; et al. Self-Assembly of Cyclodextrins and Their Complexes in Aqueous Solutions. J. Pharm. Sci. 2016, 105, 2556-2569. [CrossRef]

159. Zhu, X.; Wu, G.; Chen, D. Molecular Dynamics Simulation of Cyclodextrin Aggregation and Extraction of Anthracene from Non-Aqueous Liquid Phase. J. Hazard. Mater. 2016, 320, 169-175. [CrossRef]

160. Bonnet, P.; Jaime, C.; Morin-Allory, L. Structure and Thermodynamics of $\alpha-, \beta-$, and $\gamma$-Cyclodextrin Dimers. Molecular Dynamics Studies of the Solvent Effect and Free Binding Energies. J. Org. Chem. 2002, 67, 8602-8609. [CrossRef]

161. Krois, D.; Brinker, U.H. Circular Dichroism of Cyclodextrin Complexes; Wiley-VCH: Weinheim, Germany, 2006.

162. Hernández, R.; Rusa, M.; Rusa, C.C.; López, D.; Mijangos, C.; Tonelli, A.E. Controlling PVA Hydrogels with $\gamma$-Cyclodextrin. Macromolecules 2004, 37, 9620-9625. [CrossRef]

163. Do, T.T.; Van Hooghten, R.; Van den Mooter, G. A Study of the Aggregation of Cyclodextrins: Determination of the Critical Aggregation Concentration, Size of Aggregates and Thermodynamics Using Isodesmic and K2-K Models. Int. J. Pharm. 2017, 521, 318-326. [CrossRef]

164. Valente, A.J.M.; Carvalho, R.A.; Murtinho, D.; Söderman, O. Molecular Dynamics of Cyclodextrins in Water Solutions from NMR Deuterium Relaxation: Implications for Cyclodextrin Aggregation. Langmuir 2017, 33, 8233-8238. [CrossRef]

165. Valente, A.J.M.; Carvalho, R.A.; Söderman, O. Do Cyclodextrins Aggregate in Water? Insights from NMR Experiments. Langmuir 2015, 31, 6314-6320. [CrossRef] [PubMed]

166. He, Y.; Fu, P.; Shen, X.; Gao, H. Cyclodextrin-Based Aggregates and Characterization by Microscopy. Micron 2008, 39, 495-516. [CrossRef] [PubMed]

167. Dodziuk, H.; Danikiewicz, W.; Grabner, G.; Krois, D.; Brinker, U.H.; Bilewicz, R.; Chmurski, K.; Kunitake, M.; Ohira, A. Other Physicochemical Methods. In Cyclodextrins and Their Complexes; John Wiley \& Sons, Ltd.: Hoboken, NJ, USA, 2006; pp. 255-332, ISBN 978-3-527-60898-0.

168. Jansook, P.; Moya-Ortega, M.D.; Loftsson, T. Effect of Self-Aggregation of $\gamma$-Cyclodextrin on Drug Solubilization. J. Incl. Phenom. Macrocycl. Chem. 2010, 68, 229-236. [CrossRef]

169. Muankaew, C.; Saokham, P.; Jansook, P.; Loftsson, T. Self-Assembly of Cyclodextrin Complexes: Detection, Obstacles and Benefits. Die Pharm.-Int. J. Pharm. Sci. 2020, 75, 307-312. [CrossRef]

170. Bikádi, Z.; Kurdi, R.; Balogh, S.; Szemán, J.; Hazai, E. Aggregation of Cyclodextrins as an Important Factor to Determine Their Complexation Behavior. Chem. Biodivers. 2006, 3, 1266-1278. [CrossRef] [PubMed]

171. Eggersdorfer, M.; Wyss, A. Carotenoids in Human Nutrition and Health. Arch. Biochem. Biophys. 2018, 652, 18-26. [CrossRef]

172. Johnson, E.J. The Role of Carotenoids in Human Health. Nutr. Clin. Care Off. Publ. Tufts Univ. 2002, 5, 56-65. [CrossRef]

173. Huang, T.; Zhao, Q.; Su, Y.; Ouyang, D. Investigation of Molecular Aggregation Mechanism of Glipizide/Cyclodextrin Complexation by Combined Experimental and Molecular Modeling Approaches. Asian J. Pharm. Sci. 2019, 14, 609-620. [CrossRef]

174. Chun, J.-Y.; You, S.-K.; Lee, M.-Y.; Choi, M.-J.; Min, S.-G. Characterization of $\beta$-Cyclodextrin Self-Aggregates for Eugenol Encapsulation. Int. J. Food Eng. 2012, 8. [CrossRef]

175. Jo, Y.-J.; Cho, H.-S.; Choi, M.-J.; Min, S.-G.; Chun, J.-Y. Effect of Various Concentration of $\beta$-Cyclodextrin Inclusion Complexes Containing Trans-Cinnamaldehyde by Molecular Self-Assembly. Int. J. Food Eng. 2015, 11, 619-627. [CrossRef]

176. Rodrigues Sá Couto, A.; Ryzhakov, A.; Larsen, K.L.; Loftsson, T. Interaction of Native Cyclodextrins and Their Hydroxypropylated Derivatives with Carbamazepine in Aqueous Solution. Evaluation of Inclusion Complexes and Aggregates Formation. ACS Omega 2019, 4, 1460-1469. [CrossRef]

177. Ambrósio, A.F.; Soares-Da-Silva, P.; Carvalho, C.M.; Carvalho, A.P. Mechanisms of Action of Carbamazepine and Its Derivatives, Oxcarbazepine, BIA 2-093, and BIA 2-024. Neurochem. Res. 2002, 27, 121-130. [CrossRef] [PubMed]

178. Ferrazza, R.; Rossi, B.; Guella, G. DOSY-NMR and Raman Investigations on the Self-Aggregation and Cyclodextrin Complexation of Vanillin. J. Phys. Chem. B 2014, 118, 7147-7155. [CrossRef] [PubMed]

179. Stappaerts, J.; Do Thi, T.; Dominguez-Vega, E.; Somsen, G.W.; Van den Mooter, G.; Augustijns, P. The Impact of Guest Compounds on Cyclodextrin Aggregation Behavior: A Series of Structurally Related Parabens. Int. J. Pharm. 2017, 529, 442-450. [CrossRef]

180. Sayed, M.; Jha, S.; Pal, H. Complexation Induced Aggregation and Deaggregation of Acridine Orange with Sulfobutylether- $\beta$ Cyclodextrin. Phys. Chem. Chem. Phys. 2017, 19, 24166-24178. [CrossRef]

181. Kurkov, S.V.; Ukhatskaya, E.V.; Loftsson, T. Drug/Cyclodextrin: Beyond Inclusion Complexation. J. Incl. Phenom. Macrocycl. Chem. 2011, 69, 297-301. [CrossRef]

182. Cheirsilp, B.; Rakmai, J. Inclusion Complex Formation of Cyclodextrin with Its Guest and Their Applications. Biol. Eng. Med. 2017, 2, 1-6. [CrossRef] 
183. Street, K.W., Jr. Cyclodextrin Cavity Polarity and Chromatographic Implications. J. Liq. Chromatogr. 1987, 10, 655-662. [CrossRef]

184. Heredia, A.; Requena, G.; Sánchez, F.G. An Approach for the Estimation of the Polarity of the $\beta$-Cyclodextrin Internal Cavity. J. Chem. Soc. Chem. Commun. 1985, 24, 1814-1815. [CrossRef]

185. Al-Burtomani, S.K.S.; Suliman, F.O. Inclusion Complexes of Norepinephrine with $\beta$-Cyclodextrin, 18-Crown-6 and Cucurbit[7]Uril: Experimental and Molecular Dynamics Study. RSC Adv. 2017, 7, 9888-9901. [CrossRef]

186. Jara, P.; Barrientos, L.; Herrera, B.; Sobrados, I. Inclusion compounds of $\alpha$-cyclodextrin with alkylthiols. J. Chil. Chem. Soc. 2008, 53, 1474-1476. [CrossRef]

187. Paul, B.K.; Ghosh, N.; Mukherjee, S. Interaction of Bile Salts with $\beta$-Cyclodextrins Reveals Nonclassical Hydrophobic Effect and Enthalpy-Entropy Compensation. J. Phys. Chem. B 2016, 120, 3963-3968. [CrossRef] [PubMed]

188. Liu, L.; Guo, Q.-X. The Driving Forces in the Inclusion Complexation of Cyclodextrins. J. Incl. Phenom. Macrocycl. Chem. 2002, 42, 1-14. [CrossRef]

189. Shimpi, S.; Chauhan, B.; Shimpi, P. Cyclodextrins: Application in Different Routes of Drug Administration. Acta Pharm. 2005, 55, 139-156.

190. Schönbeck, C. Charge Determines Guest Orientation: A Combined NMR and Molecular Dynamics Study of $\beta$-Cyclodextrins and Adamantane Derivatives. J. Phys. Chem. B 2018, 122, 4821-4827. [CrossRef] [PubMed]

191. Lutka, A.; Gołda, B. The Effect of PH on Cyclodextrin Complexation of Trifluoperazine. Acta Pol. Pharm. 2006, 63, 3-8.

192. Béni, S.; Szakács, Z.; Csernák, O.; Barcza, L.; Noszál, B. Cyclodextrin/Imatinib Complexation: Binding Mode and Charge Dependent Stabilities. Eur. J. Pharm. Sci. 2007, 30, 167-174. [CrossRef]

193. Buvári, A.; Barcza, L. Complex Formation of Phenol, Aniline, and Their Nitro Derivatives with $\beta$-Cyclodextrin. J. Chem. Soc. Perkin Trans. 2 1988, 4, 543-545. [CrossRef]

194. Liu, L.; Song, K.-S.; Li, X.-S.; Guo, Q.-X. Charge-Transfer Interaction: A Driving Force for Cyclodextrin Inclusion Complexation. J. Incl. Phenom. Macrocycl. Chem. 2001, 40, 35-39. [CrossRef]

195. Jiménez, V.; Alderete, J.B. The Role of Charge Transfer Interactions in the Inclusion Complexation of Anionic Guests with $\alpha$-Cyclodextrin. Tetrahedron 2005, 61, 5449-5456. [CrossRef]

196. Yin, C.; Cui, Z.; Jiang, Y.; van der Spoel, D.; Zhang, H. Role of Host-Guest Charge Transfer in Cyclodextrin Complexation: A Computational Study. J. Phys. Chem. C 2019, 123, 17745-17756. [CrossRef]

197. Fumes, B.H.; Guzzo, M.R.; Machado, A.E.H.; Okano, L.T. Study of the Mode of Inclusion for 7-Hydroxyflavone in $\beta$-Cyclodextrin Complexes. J. Braz. Chem. Soc. 2016, 27, 382-391. [CrossRef]

198. Iqbal, N.; Iqbal, N. Imatinib: A Breakthrough of Targeted Therapy in Cancer. Chemother. Res. Pract. 2014, 2014, 357027. [CrossRef] [PubMed]

199. Bergeron, R.J.; Channing, M.A.; Gibeily, G.J.; Pillor, D.M. Disposition Requirements for Binding in Aqueous Solution of Polar Substrates in the Cyclohexaamylose Cavity. J. Am. Chem. Soc. 1977, 99, 5146-5151. [CrossRef]

200. Rosanske, T.W.; Connors, K.A. Stoichiometric Model of $\alpha$-Cyclodextrin Complex Formation. J. Pharm. Sci. 1980, 69, 564-567. [CrossRef] [PubMed]

201. Connors, K.A.; Lin, S.-F.; Wong, A.B. Potentiometric Study of Molecular Complexes of Weak Acids and Bases Applied to Complexes of $\alpha$-Cyclodextrin with Para -Substituted Benzoic Acids. J. Pharm. Sci. 1982, 71, 217-222. [CrossRef] [PubMed]

202. Cai, W.; Yu, Y.; Shao, X. Studies on the Interaction of $\alpha$-Cyclodextrin with Phospholipid by a Flexible Docking Algorithm. Chemom. Intell. Lab. Syst. 2006, 82, 260-268. [CrossRef]

203. Du, F.; Pan, T.; Ji, X.; Hu, J.; Ren, T. Study on the Preparation of Geranyl Acetone and $\beta$-Cyclodextrin Inclusion Complex and Its Application in Cigarette Flavoring. Sci. Rep. 2020, 10, 12375. [CrossRef]

204. Bonikowski, R.; Świtakowska, P.; Kula, J. Synthesis, Odour Evaluation and Antimicrobial Activity of Some Geranyl Acetone and Nerolidol Analogues. Flavour Fragr. J. 2015, 30, 238-244. [CrossRef]

205. Pino, J.A.; Mesa, J.; Muñoz, Y.; Martí, M.P.; Marbot, R. Volatile Components from Mango (Mangifera indica L.) Cultivars. J. Agric. Food Chem. 2005, 53, 2213-2223. [CrossRef]

206. Wang, Y.; Jiang, Z.-T.; Li, R. Complexation and Molecular Microcapsules of Litsea Cubeba Essential Oil with $\beta$-Cyclodextrin and Its Derivatives. Eur. Food Res. Technol. 2009, 228, 865-873. [CrossRef]

207. Al-Rawashdeh, N.A.F.; Al-Sadeh, K.S.; Al-Bitar, M.B. Inclusion Complexes of Sunscreen Agents with $\beta$-Cyclodextrin: Spectroscopic and Molecular Modeling Studies. J. Spectrosc. 2013, 2013, e841409. [CrossRef]

208. Steiner, T.; Saenger, W. Weak Hydrogen Bonding in Cyclodextrin Complex Stabilisation. In Current Challenges on Large Supramolecular Assemblies; Tsoucaris, G., Ed.; NATO Science Series; Springer: Dordrecht, The Netherlands, 1999; pp. 375-383, ISBN 978-94-011-5284-6.

209. Ross, P.D.; Rekharsky, M.V. Thermodynamics of Hydrogen Bond and Hydrophobic Interactions in Cyclodextrin Complexes. Biophys. J. 1996, 71, 2144-2154. [CrossRef]

210. Li, N.B.; Luo, H.Q.; Liu, S.P. Resonance Rayleigh Scattering Study of the Inclusion Complexation of Chloramphenicol with $\beta$-Cyclodextrin. Talanta 2005, 66, 495-500. [CrossRef] [PubMed]

211. Chen, C.-W.; Pavlova, J.A.; Lukianov, D.A.; Tereshchenkov, A.G.; Makarov, G.I.; Khairullina, Z.Z.; Tashlitsky, V.N.; Paleskava, A.; Konevega, A.L.; Bogdanov, A.A.; et al. Binding and Action of Triphenylphosphonium Analog of Chloramphenicol upon the Bacterial Ribosome. Antibiotics 2021, 10, 390. [CrossRef] 
212. Audino, P.G.; Masuh, H.; Zerba, E. Thermal Behaviour, Biological Activity and Conformational Study of a [Methoprene/ $\beta$ Cyclodextrin] Complex in a Smoke Generating Formulation. Molecules 2005, 10, 534-544. [CrossRef]

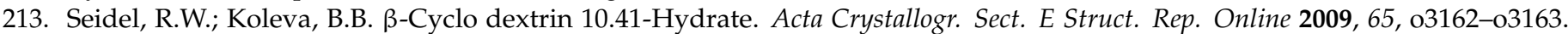
[CrossRef]

214. Pawar, S.; Shende, P.; Trotta, F. Diversity of $\beta$-Cyclodextrin-Based Nanosponges for Transformation of Actives. Int. J. Pharm. 2019, 565, 333-350. [CrossRef]

215. Rasheed, A.; Ashok Kumar, C.K.; Sravanthi, V.V.N.S.S. Cyclodextrins as Drug Carrier Molecule: A Review. Sci. Pharm. 2008, 76, 567-598. [CrossRef]

216. Pereva, S.; Nikolova, V.; Angelova, S.; Spassov, T.; Dudev, T. Water inside $\beta$-Cyclodextrin Cavity: Amount, Stability and Mechanism of Binding. Beilstein J. Org. Chem. 2019, 15, 1592-1600. [CrossRef]

217. Angelova, S.; Nikolova, V.; Pereva, S.; Spassov, T.; Dudev, T. $\alpha$-Cyclodextrin: How Effectively Can Its Hydrophobic Cavity Be Hydrated? J. Phys. Chem. B 2017, 121, 9260-9267. [CrossRef]

218. Kim, Y.W.; Kim, M.J.; Chung, B.Y.; Bang, D.Y.; Lim, S.K.; Choi, S.M.; Lim, D.S.; Cho, M.C.; Yoon, K.; Kim, H.S.; et al. Safety Evaluation and Risk Assessment Of D-Limonene. J. Toxicol. Environ. Health Part B 2013, 16, 17-38. [CrossRef]

219. Yoshii, H.; Furuta, T.; Yasunishi, A.; Hirano, H. Minimum Number of Water Molecules Required for Inclusion of D-Limonene in the Cyclodextrin Cavity. J. Biochem. 1994, 115, 1035-1037. [CrossRef] [PubMed]

220. Takeshi, F.; Hidefumi, Y.; Atsuyuki, M.; Akira, Y.; Hiroshi, H. Effect of Water and Ethanol on the Formation of Inclusion Complex for D-Limonene and Cyclodextrin System. In Biochemical Engineering for 2001; Furusaki, S., Endo, I., Matsuno, R., Eds.; Springer: Tokyo, Japan, 1992; pp. 762-764.

221. García-Río, L.; Mejuto, J.C.; Rodríguez-Dafonte, P.; Hall, R.W. The Role of Water Release from the Cyclodextrin Cavity in the Complexation of Benzoyl Chlorides by Dimethyl- $\beta$-Cyclodextrin. Tetrahedron 2010, 66, 2529-2537. [CrossRef]

222. Rácz, C.P.; Borodi, G.; Pop, M.M.; Kacso, I.; Sánta, S.; Tomoaia-Cotisel, M. Structure of the Inclusion Complex of $\beta$-Cyclodextrin with Lipoic Acid from Laboratory Powder Diffraction Data. Acta Crystallogr. B 2012, 68, 164-170. [CrossRef] [PubMed]

223. Andreaus, J.; Dalmolin, M.C.; de Oliveira, I.B., Jr.; Barcellos, I.O. Aplicação de ciclodextrinas em processos têxteis. Quím. Nova 2010, 33, 929-937. [CrossRef]

224. Xu, J. Applications in the Textile Industry. In Cyclodextrins; World Scientific: Singapore, 2017; pp. 209-230, ISBN 978-981-322-965-5.

225. Savarino, P.; Viscardi, G.; Quagliotto, P.; Montoneri, E.; Barni, E. Reactivity and Effects of Cyclodextrins in Textile Dyeing. Dyes Pigment. 1999, 42, 143-147. [CrossRef]

226. Hu, X.; Hu, Y.; Xu, G.; Li, M.; Zhu, Y.; Jiang, L.; Tu, Y.; Zhu, X.; Xie, X.; Li, A. Green Synthesis of a Magnetic $\beta$-Cyclodextrin Polymer for Rapid Removal of Organic Micro-Pollutants and Heavy Metals from Dyeing Wastewater. Environ. Res. 2020, 180, 108796. [CrossRef]

227. Xu, M.-Y.; Jiang, H.-L.; Xie, Z.-W.; Li, Z.-T.; Xu, D.; He, F.-A. Highly Efficient Selective Adsorption of Anionic Dyes by Modified $\beta$-Cyclodextrin Polymers. J. Taiwan Inst. Chem. Eng. 2020, 108, 114-128. [CrossRef]

228. Teng, M.; Li, F.; Zhang, B.; Taha, A.A. Electrospun Cyclodextrin-Functionalized Mesoporous Polyvinyl Alcohol/SiO2 Nanofiber Membranes as a Highly Efficient Adsorbent for Indigo Carmine Dye. Colloids Surf. Physicochem. Eng. Asp. 2011, 385, 229-234. [CrossRef]

229. Crupi, V.; Ficarra, R.; Guardo, M.; Majolino, D.; Stancanelli, R.; Venuti, V. UV-Vis and FTIR-ATR Spectroscopic Techniques to Study the Inclusion Complexes of Genistein with $\beta$-Cyclodextrins. J. Pharm. Biomed. Anal. 2007, 44, 110-117. [CrossRef] [PubMed]

230. Abdel-Halim, E.S.; Abdel-Mohdy, F.A.; Fouda, M.M.G.; El-Sawy, S.M.; Hamdy, I.A.; Al-Deyab, S.S. Antimicrobial Activity of Monochlorotriazinyl- $\beta$-Cyclodextrin/Chlorohexidin Diacetate Finished Cotton Fabrics. Carbohydr. Polym. 2011, 86, 1389-1394. [CrossRef]

231. Marques, H.M.C. A Review on Cyclodextrin Encapsulation of Essential Oils and Volatiles. Flavour Fragr. J. 2010, 25, 313-326. [CrossRef]

232. Lis, M.J.; García Carmona, Ó.; García Carmona, C.; Maestá Bezerra, F. Inclusion Complexes of Citronella Oil with $\beta$-Cyclodextrin for Controlled Release in Biofunctional Textiles. Polymers 2018, 10, 1324. [CrossRef]

233. Popescu, V.; Petrea, M.; Popescu, A. Multifunctional Finishing of Cotton with Compounds Derived from MCT- $\beta-C D$ and Quantification of Effects Using MLR Statistical Analysis. Polymers 2021, 13, 410. [CrossRef]

234. Cireli, A.; Yurdakul, B. Application of Cyclodextrin to the Textile Dyeing and Washing Processes. J. Appl. Polym. Sci. 2006, 100, 208-218. [CrossRef]

235. Kacem, I.; Laurent, T.; Blanchemain, N.; Neut, C.; Chai, F.; Haulon, S.; Hildebrand, H.F.; Martel, B. Dyeing and Antibacterial Activation with Methylene Blue of a Cyclodextrin Modified Polyester Vascular Graft. J. Biomed. Mater. Res. A 2014, 102, $2942-2951$. [CrossRef]

236. Park, J.S.; Kim, I.-S. Use of $\beta$-Cyclodextrin in an Antimigration Coating for Polyester Fabric. Color. Technol. 2013, 129, 347-351. [CrossRef]

237. Chen, J.; Liu, M.; Pu, Y.; Wang, C.; Han, J.; Jiang, M.; Liu, K. The Preparation of Thin-Walled Multi-Cavities $\beta$-Cyclodextrin Polymer and Its Static and Dynamic Properties for Dyes Removal. J. Environ. Manag. 2019, 245, 105-113. [CrossRef]

238. Szejtli, J. Cyclodextrins in Foods, Cosmetics and Toiletries. In Proceedings of the First International Symposium on Cyclodextrins, Budapest, Hungary, 30 September-2 October 1981; Szejtli, J., Ed.; Springer: Dordrecht, The Netherlands, 1982; pp. 469-480.

239. Hedges, A.R. Industrial Applications of Cyclodextrins. Chem. Rev. 1998, 98, 2035-2044. [CrossRef] 
240. Maskooki, A.M.; Beheshti, S.H.R.; Valibeigi, S.; Feizi, J. Effect of Cholesterol Removal Processing Using $\beta$-Cyclodextrin on Main Components of Milk. Int. J. Food Sci. 2013, 2013, e215305. [CrossRef] [PubMed]

241. Singh, M.; Sharma, R.; Banerjee, U.C. Biotechnological Applications of Cyclodextrins. Biotechnol. Adv. 2002, 20, 341-359. [CrossRef]

242. Irie, T.; Uekama, K. Cyclodextrins in Peptide and Protein Delivery. Adv. Drug Deliv. Rev. 1999, 36, 101-123. [CrossRef]

243. Zhao, Q.; Temsamani, J.; Agrawal, S. Use of Cyclodextrin and Its Derivatives as Carriers for Oligonucleotide Delivery. Antisense Res. Dev. 1995, 5, 185-192. [CrossRef]

244. Bait, O.; Si-Ameur, M. Enhanced Heat and Mass Transfer in Solar Stills Using Nanofluids: A Review. Sol. Energy 2018, 170, 694-722. [CrossRef]

245. Li, X.; Chen, W.; Zou, C. An Experimental Study on $\beta$-Cyclodextrin Modified Carbon Nanotubes Nanofluids for the Direct Absorption Solar Collector (DASC): Specific Heat Capacity and Photo-Thermal Conversion Performance. Sol. Energy Mater. Sol. Cells 2020, 204, 110240. [CrossRef]

246. Fuskele, V.; Sarviya, R.M. Recent Developments in Nanoparticles Synthesis, Preparation and Stability of Nanofluids. Mater. Today Proc. 2017, 4, 4049-4060. [CrossRef]

247. Taylor, R.A.; Phelan, P.E.; Otanicar, T.P.; Walker, C.A.; Nguyen, M.; Trimble, S.; Prasher, R. Applicability of Nanofluids in High Flux Solar Collectors. J. Renew. Sustain. Energy 2011, 3, 023104. [CrossRef]

248. Feng, J.; Miedaner, A.; Ahrenkiel, P.; Himmel, M.E.; Curtis, C.; Ginley, D. Self-Assembly of Photoactive TiO2-Cyclodextrin Wires J. Am. Chem. Soc. 2005, 127, 14968-14969. [CrossRef]

249. Willner, I.; Eichen, Y. Titanium Dioxide and Cadmium Sulfide Colloids Stabilized by. Beta.-Cyclodextrins: Tailored SemiconductorReceptor Systems as a Means to Control Interfacial Electron-Transfer Processes. J. Am. Chem. Soc. 1987, 109, 6862-6863. [CrossRef]

250. Sharavath, V.; Sarkar, S.; Gandla, D.; Ghosh, S. Low Temperature Synthesis of TiO2- $\beta$-Cyclodextrin-Graphene Nanocomposite for Energy Storage and Photocatalytic Applications. Electrochim. Acta 2016, 210, 385-394. [CrossRef]

251. Guo, Y.; Guo, S.; Ren, J.; Zhai, Y.; Dong, S.; Wang, E. Cyclodextrin Functionalized Graphene Nanosheets with High Supramolecular Recognition Capability: Synthesis and Host-Guest Inclusion for Enhanced Electrochemical Performance. ACS Nano 2010, 4, 4001-4010. [CrossRef] [PubMed]

252. Alam, A.U.; Qin, Y.; Catalano, M.; Wang, L.; Kim, M.J.; Howlader, M.M.R.; Hu, N.-X.; Deen, M.J. Tailoring MWCNTs and $\beta$-Cyclodextrin for Sensitive Detection of Acetaminophen and Estrogen. ACS Appl. Mater. Interfaces 2018, 10, 21411-21427. [CrossRef]

253. Kor, K.; Zarei, K. $\beta$-Cyclodextrin Incorporated Carbon Nanotube Paste Electrode as Electrochemical Sensor for Nifedipine. Electroanalysis 2013, 25, 1497-1504. [CrossRef]

254. Yin, T.; Wei, W.; Zeng, J. Selective Detection of Dopamine in the Presence of Ascorbic Acid by Use of Glassy-Carbon Electrodes Modified with Both Polyaniline Film and Multi-Walled Carbon Nanotubes with Incorporated $\beta$-Cyclodextrin. Anal. Bioanal. Chem. 2006, 386, 2087-2094. [CrossRef] [PubMed]

255. Gandomi, F.; Marzi Khosrowshahi, E.; Sohouli, E.; Aghaei, M.; Saleh Mohammadnia, M.; Naghian, E.; Rahimi-Nasrabadi, M. Linagliptin Electrochemical Sensor Based on Carbon Nitride- $\beta$-Cyclodextrin Nanocomposite as a Modifier. J. Electroanal. Chem. 2020, 876, 114697. [CrossRef]

256. Xu, X.; Liu, Z.; Zhang, X.; Duan, S.; Xu, S.; Zhou, C. $\beta$-Cyclodextrin Functionalized Mesoporous Silica for Electrochemical Selective Sensor: Simultaneous Determination of Nitrophenol Isomers. Electrochim. Acta 2011, 58, 142-149. [CrossRef]

257. Zhou, Y.; Zhao, J.; Li, S.; Guo, M.; Fan, Z. An Electrochemical Sensor for the Detection of P-Nitrophenol Based on a CyclodextrinDecorated Gold Nanoparticle-Mesoporous Carbon Hybrid. Analyst 2019, 144, 4400-4406. [CrossRef]

258. Selvam, S.; Balamuralitharan, B.; Karthick, S.N.; Savariraj, A.D.; Hemalatha, K.V.; Kim, S.-K.; Kim, H.-J. Novel High-Temperature Supercapacitor Combined Dye Sensitized Solar Cell from a Sulfated $\beta$-Cyclodextrin/PVP/MnCO3 Composite. J. Mater. Chem. A 2015, 3, 10225-10232. [CrossRef]

259. Gao, S.; Wang, L. Application of Cyclodextrin in Environmental Science. Huanjing Kexue Jinzhan 1998, 6, 80-86.

260. Gibson, L.T. Mesosilica Materials and Organic Pollutant Adsorption: Part B Removal from Aqueous Solution. Chem. Soc. Rev. 2014, 43, 5173-5182. [CrossRef] [PubMed]

261. Morin-Crini, N.; Fourmentin, M.; Fourmentin, S.; Torri, G.; Crini, G. Silica Materials Containing Cyclodextrin for Pollutant Removal. In Cyclodextrin Applications in Medicine, Food, Environment and Liquid Crystals; Environmental Chemistry for a Sustainable World; Fourmentin, S., Crini, G., Lichtfouse, E., Eds.; Springer International Publishing: Cham, Switzerland, 2018; pp. 149-182, ISBN 978-3-319-76162-6

262. Morin-Crini, N.; Fourmentin, M.; Fourmentin, S.; Torri, G.; Crini, G. Synthesis of Silica Materials Containing Cyclodextrin and Their Applications in Wastewater Treatment. Environ. Chem. Lett. 2019, 17, 683-696. [CrossRef]

263. Huang, T.; Sheng, G.; Manchanda, P.; Emwas, A.H.; Lai, Z.; Nunes, S.P.; Peinemann, K.-V. Cyclodextrin Polymer Networks Decorated with Subnanometer Metal Nanoparticles for High-Performance Low-Temperature Catalysis. Sci. Adv. 2019, 5, eaax6976. [CrossRef] [PubMed] 